\title{
Confined Catalysis: Progress and Prospects in Energy Conversion
}

\author{
Tofik Ahmed Shifa* and Alberto Vomiero*
}

Space confined catalysis has emerged as viable strategy for achieving potent and efficient catalysts in various important reactions. It offers a means of creating unique nanoscale chemical environments partitioned from the surrounding bulk space. This gives rise to the phenomena of nanoconfinement, where the energetics and kinetics of catalytic reactions can be modulated upon confining the catalysts in a particular site. Various scaffolds have been reported so far for confinement. Among these, void spaces under the cover of 2D materials, van der Waals (vdW) gaps of layered 2D materials, nanotubes, and porous surfaces have recently won copious attention. In this review, the concept of space confinement with respect to its effect on the electronic and structural properties of a catalyst is discussed. Emphasis is devoted to the catalysis of water splitting and $\mathrm{CO}_{2}$ reduction reactions. The progress in the design and applications of space confined catalysts is then traced. Finally, a discussion of emerging issues yet to be explored for this strategy to achieve a high efficiency, and future directions with the potential to become a new hotspots are presented.

\section{Introduction}

Nowadays, there is a significant drive to relinquish our dependence on fossil fuels and minimize the emission of carbon dioxide. ${ }^{[1,2]}$ The production of hydrogen $\left(\mathrm{H}_{2}\right)$ via water splitting and the reduction of $\mathrm{CO}_{2}$ to value added organic compounds are significant research directions to ensuring the greenest route for powering the globe. ${ }^{[3,4]}$ However, these two important reactions are thermodynamically challenging, requiring rational design of efficient catalysts entirely based on Earth abundant elements. Scientists are making considerable efforts in this regard. Plethora of materials such as Earth-abundant transition metals, ${ }^{[5,6]}$ their oxides, ${ }^{[7,8]}$

Dr. T. A. Shifa, Prof. A. Vomiero

Division of Materials Science

Department of Engineering Sciences and Mathematics

Luleå University of Technology

SE-97187 Luleå, Sweden

E-mail: tofik.ahmed.shifa@ltu.se; alberto.vomiero@ltu.se

Prof. A. Vomiero

Department of Molecular Sciences and Nanosystems

Ca' Foscari University of Venice

Via Torino 155, 30170 Venezia Mestre, Italy

E-mail: alberto.vomiero@unive.it

The ORCID identification number(s) for the author(s) of this article can be found under https://doi.org/10.1002/aenm.201902307.

DOI: 10.1002/aenm.201902307 chalcogenides, ${ }^{[9]}$ nitrides, ${ }^{[10]}$ phosphides, ${ }^{[11]}$ carbides, ${ }^{[12]}$ and metal free catalysts (graphene, graphitic- $\left.\mathrm{C}_{3} \mathrm{~N}_{4}\right)^{[13,14]}$ have been investigated so far. Apart from exploring their intrinsic properties, various strategies including doping, ${ }^{[15,16]}$ heterostructuring, ${ }^{[17-19]}$ edge engineering, ${ }^{[20]}$ phase modulation, ${ }^{[21,22]}$ etc., have also been followed to optimize the energetics and kinetics of the catalystadsorbate interaction. These strategies are believed to result in at least one of the three goals, which ultimately lead to enhanced performance: i) increasing the number of active sites, ii) improving the intrinsic active sites, and iii) enhancing the electrical conductivity. Interestingly, some families of materials exhibit unique and intriguing properties offering great opportunities for boosting the catalytic performance in electro(photo) chemical reactions. For instance, the layered feature of transition metal dichalcogenides, ${ }^{[23]}$ the Ptresemblance of transition metal carbides and nitrides, ${ }^{[24,25]}$ the exceptional role of $\mathrm{P}$ in transition metal phosphides ${ }^{[11,26]}$ can be mentioned. Likewise, there are materials with cavities in their structure, which stimulated the intensive exploration from various research groups. ${ }^{[27-31]}$ These cavities can be the van der Waals (vdW) gaps in layered 2D materials (2D vdW gaps), spaces under 2D covers, channels in nanotubes (1D channels), porous sites (0D pores), etc. They create a pocket providing intimate contacts and favorable intermolecular interactions with the adsorbates. In addition to their prominent role as a physical nanoreactor, leading to well defined shape and size of the reaction product, confined spaces also provide specific microenvironment for the confined nucleation, growth and stabilization of intermediates or products. ${ }^{[32,33]}$ Chemical reactions in such a confined environment behave significantly differently from the ones observed in bulk solutions. ${ }^{[27,28,34]}$ It is also believed that nanoconfined fluids in 2D layered materials guarantee high power and energy densities, while maintaining high volumetric capacity in pursuit of developing efficient energy storage devices. ${ }^{[31]}$ In catalysis, space confinement has been the focus of latest research. Nanostructured materials attracted copious attention owing to their surface abundant catalytically active sites. ${ }^{[35]}$ However, down-sizing metal nanoparticles to expose most of their active sites may also induce instability at ambient conditions as ultrahigh amount of surface atoms are exposed. ${ }^{[36]}$ This may degrade the catalytic activity after repeated cycles and 
must be confronted to prevent the deterioration of surface exposed atoms. One of the most promising ways is isolating these active catalysts in confined regions such that the catalysts can directly catalyze the desired reaction and the molecules that are likely poisoning the surface of the catalysts are blocked from entering the isolated microenvironment. This can be considered as "nature inspired nanotechnology" as it mimics the host-guest interactions of enzymes by assembling nanoreactors of predefined shape and size. ${ }^{[37]}$ As compared to conventional heterostructures, where the catalyst is kept in open surface and vulnerable to be corroded or leached away, the stability and selectivity of confined catalysts are greatly enhanced. The confined space should be appropriate to accommodate the ion and electron transport in the catalytic reaction, unless pressure may build up and deteriorate the kinetics. A strategy to confront this problem lies on the rational design of scaffolds with cracks, voids, edges, etc., that would serve as channels to facilitate pressure release and prevent the build-up of pressure in catalytic reaction. ${ }^{[38]}$ Figure 1 schematically depicts how a catalyst is confined in a separate environment, i.e., the cavity, and partitioned from the surrounding bulk space.

The catalytic performance in such cases is usually enhanced. This phenomenon is called confined catalysis and has recently become an emerging trend in various reaction types. It has gone through considerable developments deserving a comprehensive outlook and plausible forecasts, mainly due to the outstanding catalytic functionality in comparison to catalysts based on noble metals, which gives this new concept a potential breakthrough in the field. In this review, we first discuss the various categories of space confinement and the structural/electronic properties derived from it. We then summarize the research developments made so far in connection to catalysis, pointing out the challenges and opportunities. Eventually, we offer direction worth of investigation that would transform this emerging research trend a significant step forward.

a)

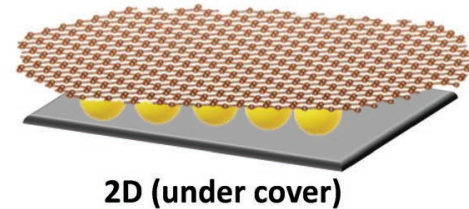

c)

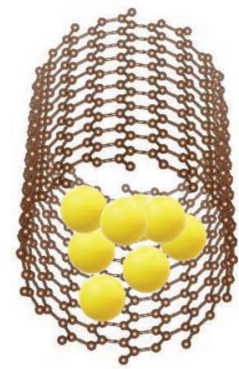

1D

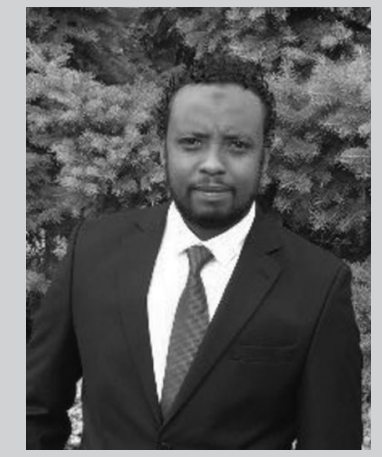

Tofik Ahmed Shifa received his B.Sc. degree (2007) in applied chemistry and M.Sc. degree (2011) in analytical chemistry from Arbaminch University and Haramaya University, respectively. After working as a lecturer at Haramaya University for 2 years, he was admitted at the University of Chinese Academy of Sciences, National Center for Nanoscience and Technology (NCNST) where he was awarded his Ph.D. in physical chemistry in 2018. Currently, he is working as a postdoctoral researcher at the Luleå University of Technology, Sweden. His research focuses on controllable synthesis and development of novel 2D layered materials for electrocatalysis or photocatalysis.

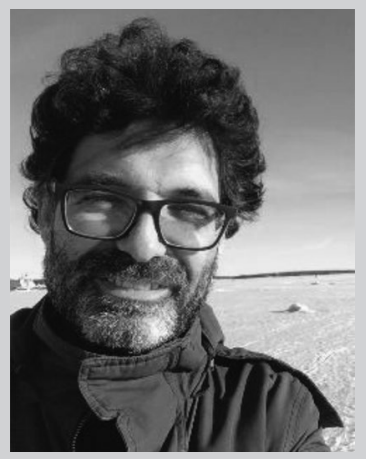

Alberto Vomiero has held the chair in experimental physics at the Luleå University of Technology, Sweden since 2014 and the chair in industrial engineering at $\mathrm{Ca}^{\prime}$ Foscari University of Venice since 2018. He was awarded his Ph.D. in electronic engineering from the University of Trento in 2003 and his degree in physics from the University of Padova in 1999. His main interests are in composite nanomaterials for environmental applications. b)

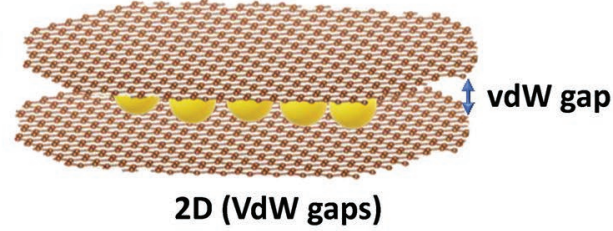

d)

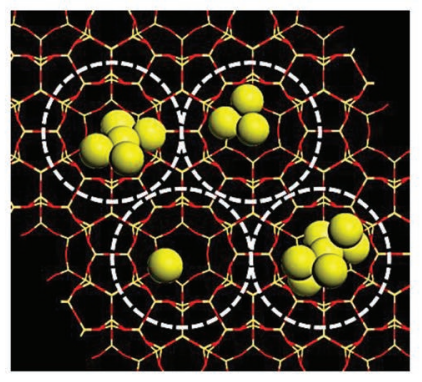

OD

Figure 1. Different ways of nanoconfinement: a) Under 2D cover. b) vdW gaps of 2D layered materials. c) Nanotube channels. d) Porous sites. Reproduced with permission. ${ }^{[39]}$ Copyright 2017, Macmillan Publishers Limited, part of Springer Nature. 
a)

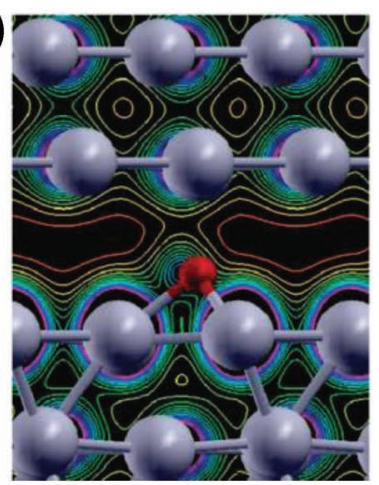

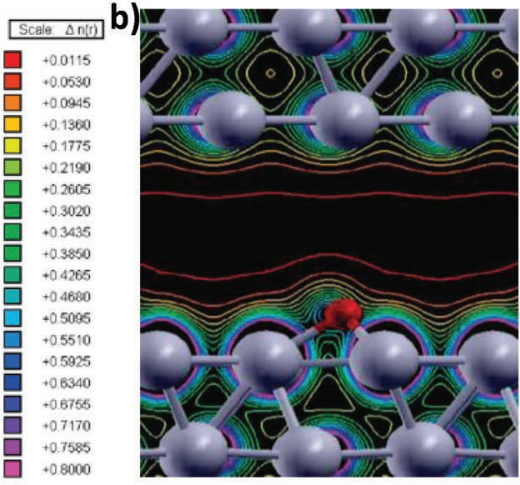

c)
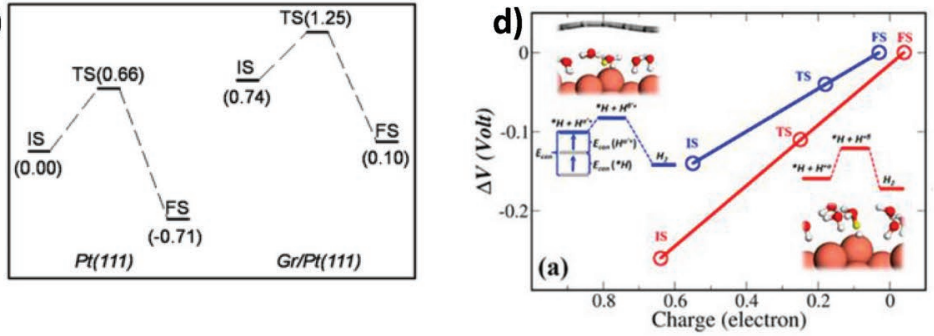

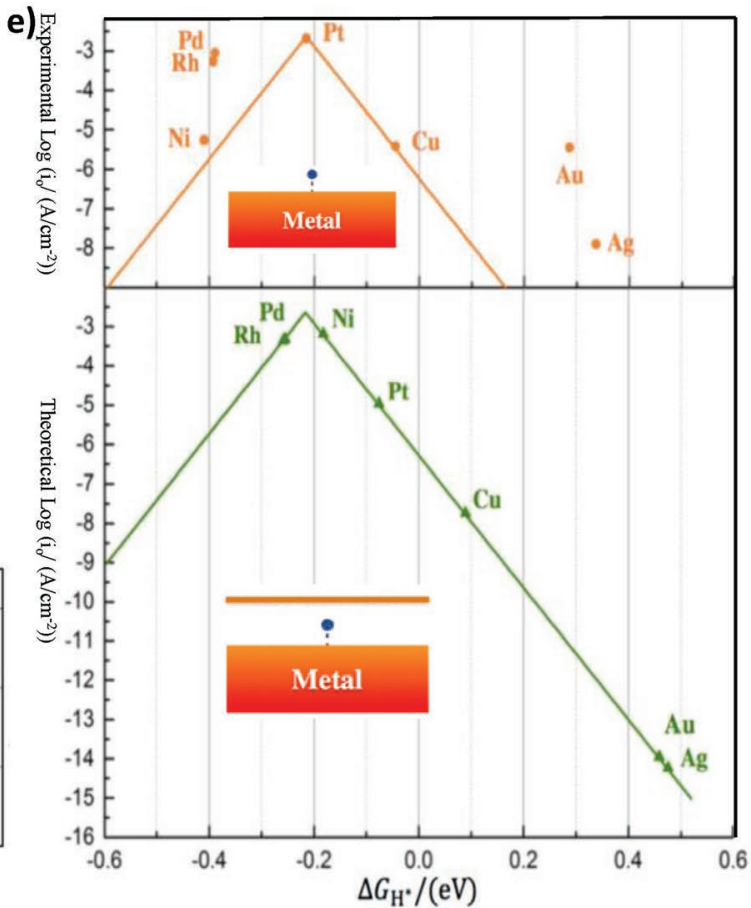

Figure 2. a) Electron density plots for small (4.12 Å) geometrical size of space confinement and b) when the distance goes beyond a certain threshold $(5.5 \AA$ A $)$ for oxygen molecule confined between two Pt slabs. Reproduced with permission. ${ }^{\left[{ }^{[3]}\right]}$ Copyright 2009, American Chemical Society. c) Results of free energy calculations for $\mathrm{CO}$ oxidation on $\mathrm{Pt}(111)$ surface under graphene cover and on open surface. Values in the brackets are in unit of electron volt. Reproduced with permission. ${ }^{[45]}$ Copyright 2014, USNAS. d) Comparison of Heyrovsky reaction taking place in an open system (red) and inside a confined system (blue). The confinement energy endows more favorable reaction energies and lower electrochemical kinetic barrier for the confined system. Reproduced with permission. ${ }^{[48]}$ Copyright 2019, American Chemical Society. e) Experimental volcano plots of adsorption free energy versus $\log \left(i_{0}\right)$ for HER on metal (111) surfaces with vdW corrections (upper panel). Calculated volcano plots of the same situation but in confined zone under graphene cover (lower panel). Reproduced with permission. ${ }^{[4]}$ Copyright 2016, American Chemical Society.

\subsection{Structural and Electronic Properties upon Confinement}

Reactivity is enhanced in confined systems due to the confinement of the whole or parts of the catalyst and adsorbates, resulting in the modification of the relevant electronic states. The combined effect of surface area and Coulombic interaction in confined catalysis plays a pivotal role in tailoring the catalytic activity. In fact, the favorable interaction (the attraction between electrostatically opposite charges) of the incoming nanoparticle and the functional groups of the confining framework would assist the self- assembly of nanoparticles in the desired space. ${ }^{[40]}$ The difference in electronic structures and spatial confinement results in stronger strains and deformations. Xiao et al., ${ }^{[41]}$ have realized the downshift of d-band states of the confined Fe clusters in carbon nanotube (CNT) channel. Similarly, broader d-bands and lower density of states (DOS) at the Fermi level have been realized in a system of a Ti monolayer over Pt, when interacting with another Pt surface at distances $<6 \AA$, suggesting the remarkable impact of confinement on the electronic states. ${ }^{[42]}$ The best descriptors in evaluating the catalytic performances are the adsorption energies and energy barriers of adsorbate, which are influenced by spatial confinement. In their computational report, ${ }^{[43]}$ Ramirez-Caballero and Balbuena elucidated the variation in adsorption energy of $\mathrm{O}_{2}$ molecule confined between two Pt slabs with respect to the size of confinement. The $\mathrm{O}_{2}$ molecule is located above one Pt-surface and beneath the other one. The electronic density plot depicted in Figure 2a shows the overlap of electronic states among both $\mathrm{Pt}$ surfaces and the oxygen atom, which weakens the adsorption strength of oxygen atom. When the Pt-Pt distance increases $(>5.5 \AA)$, the condition resembles open surface and hence the electronic interaction phenomena in the confined system diminishes (Figure 2b). ${ }^{[3]}$ It is important to define a term "confinement energy" here, as it is the one responsible for the advent of new properties. It is the difference in energy of adsorption (between the reaction intermediates and the catalyst) with and without confinement. For instance, in the work by Li et al., ${ }^{[44]}$ they defined the confinement energy $\left(E_{\text {con }}\right)$ in the system of Pt under graphene $(\mathrm{Gr})$ cover, as:

$E_{\text {con }}=E_{\text {ad }}(\mathrm{w} / \mathrm{Gr})-E_{\text {ad }}(\mathrm{wo} / \mathrm{Gr})$

where, $E_{\text {con }}$ is the confinement energy, $E_{\text {ad }}$ is the adsorption energy with (w/Gr) and without (wo/Gr) confinement. $E_{\text {con }}$ was computed to be $0.44 \mathrm{eV}$ for $\mathrm{CO}$ adsorption, meaning that the $E_{\text {ad }}(\mathrm{CO})$ decreases from $-1.94 \mathrm{eV}$ on the bare Pt(111) surface to $-1.50 \mathrm{eV}$ in the space between $\mathrm{Gr}$ and $\mathrm{Pt}(111)$ (i.e., under 2D cover). The $\mathrm{C}-\mathrm{O}$ bond in $\mathrm{CO}$ is weakened by the electronic interaction between the top graphene overlayer and the molecules of confined CO, promoting the CO oxidation. This hints the effective tunability of various catalytic reactions in confined environment. ${ }^{[4]}$ What is even more unique in this setup is the 
easy modification of the surface potential. Confining metal surfaces under graphene can effectively tune the surface potential and it is controllable by varying the distance between graphene and the metal. It is believed that this effect is similar to applying an external electric field onto a solid electrode, highly resembling what is happening in electrocatalysis. Figure 2c compares the energy profiles of $\mathrm{CO}$ catalytic oxidation on bare $\mathrm{Pt}(111)$ and $\mathrm{Pt}(111)$ covered by graphene $\mathrm{Gr} / \mathrm{Pt}(111) \cdot{ }^{[45]}$ The energy barrier in the confined system is reduced to $0.51 \mathrm{eV}$ (as compared to $0.66 \mathrm{eV}$ in bare $\mathrm{Pt}$ ), meaning that the graphene overlayer decreases the binding energy between the catalyst and the adsorbate; and so the reaction proceeds via a smaller reaction barrier. Bao's group ${ }^{[46]}$ has reported relatively stronger interaction between the metal and the 2D cover in the case of Pt covered by h-BN. The polar h-BN sheet may interact more strongly with the metal, than the nonpolar graphene, contributing to a better electronic interaction. For this reason, the extent of interaction depends on the interface materials properties, which in turn tune the reactivity in the confined zone. Moreover, the energetics and kinetics of hydrogen adsorption on various metal surfaces under graphene have also been studied computationally. ${ }^{[47]}$

The graphene layer generally weakens the $\mathrm{H}$ binding energy by different amounts for different metals. It is noteworthy that there is an improvement in the charge transfer efficiency in the confined space due to the induced confinement field, which in turn enhances the electrochemical capacitance. Thus, smaller applied voltage is needed to produce the same amount of current in electrocatalysis in the case of a confined system. As shown in Figure 2d, the Heyrovsky step in hydrogen evolution reaction proceeds through a more favorable energetic scheme and with a lower kinetic barrier in a confined environment. ${ }^{[48]}$ The Ni atom under graphene cover is theoretically computed to demonstrate hydrogen evolution reaction (HER) catalysis peaked at volcano plot comparable to the precious bare Pt. Normally, Ni surface in open environment shows moderate HER activity (Figure 2e). After being confined under the graphene layer, the high mobility of $\mathrm{H}$ on bare $\mathrm{Ni}(111)$ is remarkably restricted. That is, $\mathrm{H}$ prefers to stay in the confined zone rather than to diffuse into the exterior surfaces. In general, confined environment considerably alters the chemical reactions due to the changes in adsorption, geometrical constraints, surface potential energy, etc. It is, therefore, noteworthy that catalysis under confinement can bring a versatile platform to tune the energetics and kinetics of catalytic reactions. In the subsequent section, we discuss the various confinement modes and the advances made therein.

\section{Platforms for Confinement}

A geometrically separate and well-defined environment should be set to bring a space confinement phenomenon into action. This concept has been experimented for catalysis using various scaffolds as a confining boundary. Most frequently utilized platforms are vdW gaps in layered 2D materials, spaces under 2D cover, channels in nanotubes (1D) and porous sites (0D) in zeolite or metal organic frameworks. In the context of this review, the denotations $0 \mathrm{D}, 1 \mathrm{D}$, and $2 \mathrm{D}$ indicate that the reaction molecules are confined in three, two, and one dimension, respectively.

\subsection{D Materials}

The discovery of graphene in $2004^{[49]}$ has stimulated the widespread investigation of many other 2D materials. ${ }^{[50]}$ Particularly, the intriguing structural and electronic properties of layered 2D materials have prompted intense exploration in search for efficient catalysts. ${ }^{[17,51]}$ Their band structure changes drastically as they are thinned to monolayer thickness, substantiating the ease of electronic tunability via exfoliation. They can be optimized to possess high surface area and maximal exposure of active sites through various controllable synthesis methods. Very recently, layered $2 \mathrm{D}$ materials such as graphitic- $\mathrm{C}_{3} \mathrm{~N}_{4},{ }^{[52]}$ $\mathrm{rGO},{ }^{[53]}$ transition metal dichalcogenides (TMDs), ${ }^{[54]}$ metal phosphorus trichalcogenides $\left(\mathrm{MPX}_{3}\right)^{[55-58]}$ have emerged as promising candidates for catalysis of water splitting and $\mathrm{CO}_{2}$ reduction reactions. In addition to being catalysts themselves, they also serve as suitable hosts to confine other catalysts in various forms and further boost the catalytic performance. The strategy of confining single atom catalysts on these platforms has been duly reviewed elsewhere. ${ }^{[59]}$ The unique geometric and electronic structures of 2D materials can tune the catalytic performance of the confined single atoms. Correspondingly, the confined single atoms can in turn affect the intrinsic catalytic activity of the 2D host. Our focus in this particular topic aims at highlighting space confinements based on 2D materials that have recently become an emerging trend, allowing the confinement of nanostructured catalysts other than single atoms. In this context, confined catalysis based on 2D materials can be considered either in the space under a 2D cover (Figure 1a) or in the vdW gaps between two individual layers (Figure 1b).

\subsubsection{Spaces under a $2 D$ Cover}

Spaces under a 2D cover refer to the confined zone between a 2D material and the surface of an underlying support. The 2D materials are known to have strong in-plane covalent bonding, but weak out-of-plane vdW interaction. A case of interest for catalytic purposes is the decoration of a metallic substrate with a 2D monolayer. ${ }^{[60]}$ When an adlayer of 2D atomic crystals covers a metal surface, adsorbates can intercalate the 2D cover owing to its weak interaction with the metal. The distance between the 2D overlayers and the metal surfaces typically falls in the subnanometer range. ${ }^{[61]}$ The inserted molecule in this interface will have direct interaction with both the 2D cover (above it) and the metal surface (below it). This paves the way for fine tuning the catalytic reaction taking place in the confined zone. ${ }^{[62]}$ The presence of defects such as islands, domain boundaries and wrinkles on the 2D cover play crucial roles in further altering the interaction of adsorbates in the confined space. It is, therefore, important to controllably introduce defects during the synthesis of the desired 2D covers. The case of graphene islands with wrinkles on Pt (111) surface has been studied by R. Mu et al., ${ }^{[63]}$ who conducted direct visualization of $\mathrm{CO}$ reaction in the space between graphene and Pt (111) surface. Figure 3a-e collects the snapshot of the video recorded during CO insertion in the confined space. Observation on the image contrast elucidate that the graphene island becomes darker through time with exposure of CO. Moreover, no obvious change was noticed 

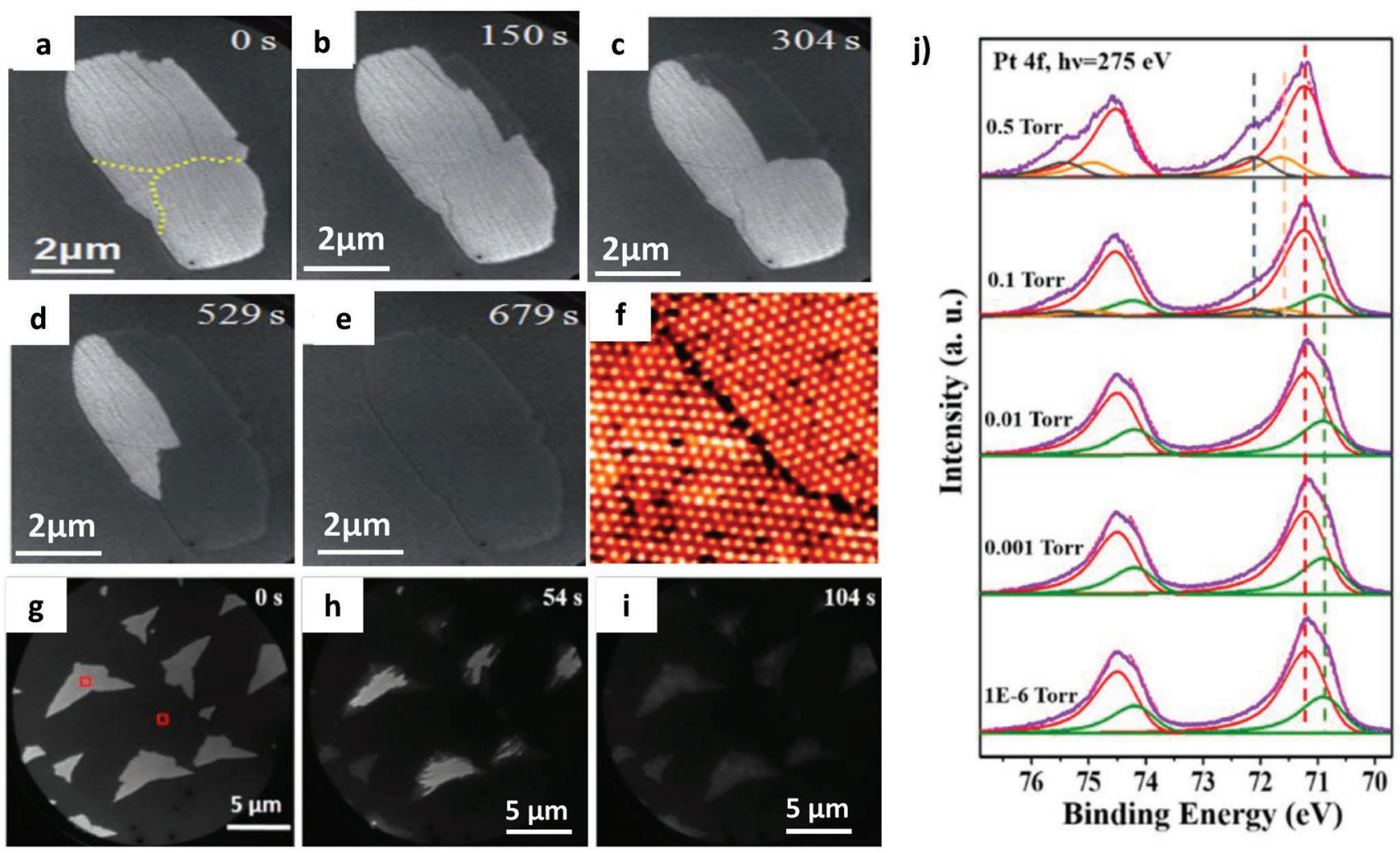

Figure 3. a-e) Snapshots of the video recorded at different times for reactions of CO confined between Pt and graphene as studied by in situ realtime low-energy electron microscopy (LEEM) with starting voltage of $1.8 \mathrm{~V}$. The dashed lines represent the wrinkles. Reproduced with permission. ${ }^{[63]}$ Copyright 2012, Wiley-VCH Verlag GmbH \& Co. KGaA, Weinheim. f) STM image of the Pt(111) surface covered by h-BN with distinguishable grain boundary and vacancies. g-i) In situ LEEM images (starting voltage $=2.25 \mathrm{~V}$ ) acquired for oxidation of $\mathrm{CO}$ confined between $\mathrm{Pt}(111)$ and $\mathrm{h}-\mathrm{BN} / \mathrm{Pt}(111)$ at various times of $\mathrm{CO}$ gas exposure. j) In situ AP-XPS of Pt $4 \mathrm{f}$ in $1 \mathrm{ML}$ h-BN/Pt(111) surface when $1 \times 10^{-6}, 0.001,0.01,0.1$, and 0.5 Torr of CO are fed into the confined region at room temperature. Reproduced with permission. ${ }^{[46]}$ Copyright 2015, American Chemical Society.

when Pt (111) surface was entirely covered by graphene, further solidifying the prominent role of defects. Similarly, defects significantly contribute to the intercalation of $\mathrm{CO}$ in the space between h-BN and Pt (111) surface.

Bao's group ${ }^{[46]}$ employed ultrahigh vacuum chemical vapor deposition to overlay h-BN sheet on Pt (111) surface. They realized the initial nucleation of h-BN islands at a few surface sites, which eventually expanded anisotropically on the surface. The domain boundaries and vacancies in the $\mathrm{h}$-BN structure are evident from the image of scanning tunneling microscopy in Figure 3f. Upon exposure to CO gas $\left(5.0 \times 10^{-8}\right.$ Torr $)$ at room temperature, a significant contrast change occurs when the islanded $\mathrm{h}$-BN covers the Pt (111), in which the adsorption starts from the island edges and then propagates to the island center. In situ microscopic study via low energy electron microscope (LEEM) revealed the direct imaging of this phenomenon (Figure $3 \mathrm{~g}-\mathrm{i}$ ). The extent of $\mathrm{h}-\mathrm{BN}$ coverage has significant impact on the reactivity of $\mathrm{CO}$ at the interface. For instance, only $10^{-8}$ Torr $\mathrm{CO}$ was required to intercalate the nanoislands of h-BN on the Pt surface. When the h-BN entirely covers the Pt surface, intercalation does not occur below 0.1 Torr CO. This can be noticed from the in situ X-ray photoelectron spectroscopy (XPS) study on the alteration of the Pt electronic states. Figure $3 j$ evidences the advent of two new peaks (72.2 and $71.6 \mathrm{eV}$ ) only at higher $\mathrm{CO}$ pressure, related to Pt surface atoms onto which CO is adsorbed. ${ }^{[64]}$ Thus, entrapping CO in the confined space between h-BN and Pt can be impeded by the full coverage of the h-BN. In addition to graphene and h-BN, g- $\mathrm{C}_{3} \mathrm{~N}_{4}$ has also been suggested as a promising candidate to serve as a $2 \mathrm{D}$ cover. ${ }^{[65]}$ When the $2 \mathrm{D}$ material is $\mathrm{g}-\mathrm{C}_{3} \mathrm{~N}_{4}$, there is an important advantageous feature, which is not present in graphene or h-BN. In fact, g- $\mathrm{C}_{3} \mathrm{~N}_{4}$ has inherent triangular pores formed by six edge nitrogen atoms, which could serve as favorable sites for the intercalation of adsorbates. By employing first-principles calculations, S. Lin ${ }^{[65]}$ group has recently simulated the oxidation of $\mathrm{CO}$ confined between Pt (111) and g- $\mathrm{C}_{3} \mathrm{~N}_{4}$. The gas molecules $\left(\mathrm{CO}\right.$ and $\mathrm{O}_{2}$ ) in the confined system can intercalate through the triangular pores of $\mathrm{g}-\mathrm{C}_{3} \mathrm{~N}_{4}$ to adsorb on $\mathrm{Pt}(111)$ and thereby enhancing the metal catalyzed reaction.

\subsubsection{Van der Waal Gaps in Layered 2D Materials}

Owing to their weak vdW bonds, layered materials can be thinned down to monolayer/few layers, to exploit the intrinsic properties of their 2D assembly, which are inherently different from their unexfoliated counterparts. ${ }^{[66]}$ This topic has been extensively studied in various families of layered materials for different applications. ${ }^{[50]}$ Nowadays, the vdW gaps have become interesting sites to confining a catalyst and tuning the 
a)

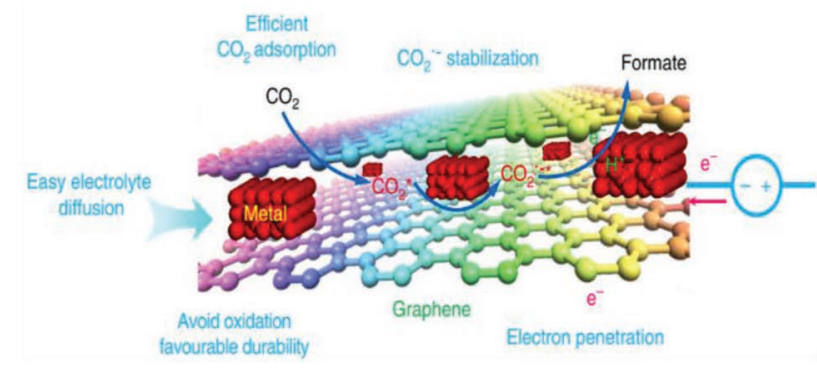

d)

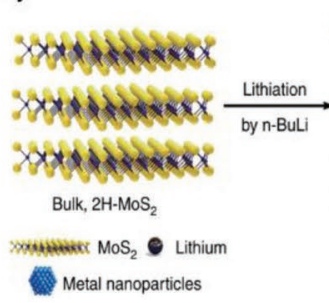

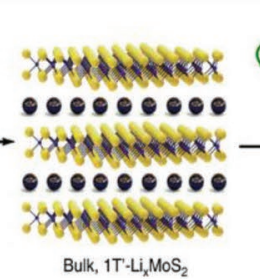

Bulk, $1 \mathrm{~T}$ - $\mathrm{Li}_{\mathrm{x}} \mathrm{MoS}_{2}$
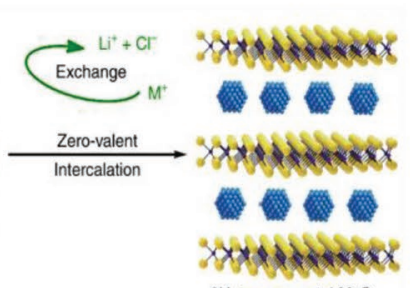

$2 \mathrm{H}$, ternary metal-MoS
(metal $=\mathrm{Pt}, \mathrm{Ru}, \mathrm{Au}, \mathrm{Pd})$
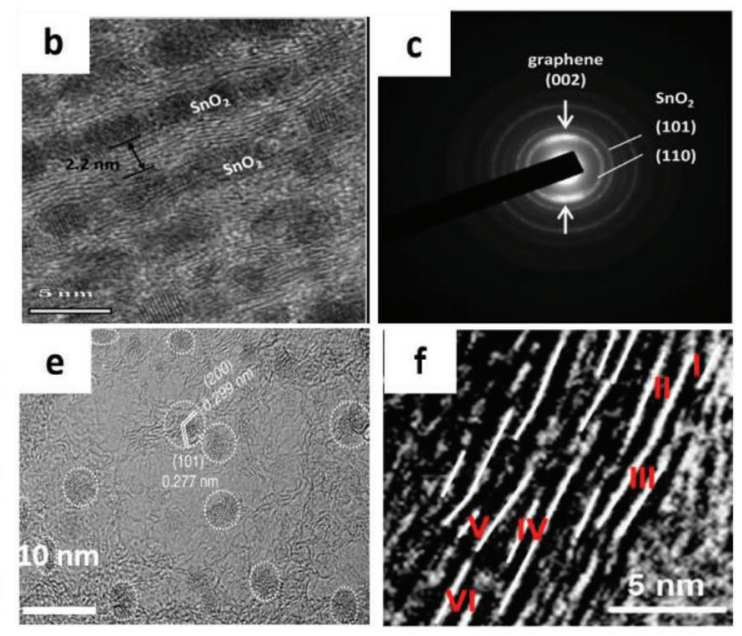

Figure 4. a) Scheme illustrating the advantages of confining ultrathin $\mathrm{Sn}$ sheet in graphene layers for $\mathrm{CO}_{2}$ electroreduction. b) $\mathrm{HRTEM}_{\mathrm{image}}$ and c) electron diffraction pattern of the $\mathrm{SnO}_{2}$ confined in graphene layers. d) Scheme of the process to confine zerovalent metal nanoparticles by an in situ reduction strategy. e) HRTEM image of elemental Sn quantum sheets confined in graphene layers. $\mathrm{f}$ ) HRTEM side view images of the (002) MoS 2 planes. The $\mathrm{Co}(\mathrm{OH})_{2}$ nanoparticles are confined in the vdW gaps of these planes. a,e) Reproduced with permission. ${ }^{[36]}$ Copyright 2016, Springer Nature. b,c) Reproduced with permission. ${ }^{[74]}$ Copyright 2013, Elsevier B.V. d) Reproduced with permission. ${ }^{[38]}$ Copyright 2016, Springer Nature. f) Reproduced with permission. ${ }^{[72]}$ Copyright 2018, American Chemical Society.

energetics and kinetics of catalysis. ${ }^{[67]}$ Layered materials such as graphene ${ }^{[68-71]}$ and transition metal dichalcogenides ${ }^{[38,72,73]}$ have so far been employed as hosts to exploit these advantages. They possess enough space in their vdW gaps so that the adsorbate species can freely diffuse into/out of the confined domain (Figure 4a). This setup favors the enhancement of catalytic performance particularly for those catalysts that are vulnerable to instabilities in an open environment. Figure $4 \mathrm{~b}$ shows the cross-sectional high-resolution transmission electron microscopy (HRTEM) image for $\mathrm{SnO}_{2}$ nanoparticles entrapped in the void space of graphene layer with thickness of $2.2 \mathrm{~nm}$ (about six graphene monolayers). The diffraction ring related to $(002)$ graphene is evidenced in the selected area electron diffraction pattern to appear on top and bottom (110) ring of $\mathrm{SnO}_{2}$ (Figure 4c). ${ }^{[74}$ These results suggest the possibility of confining metal oxides such as $\mathrm{SnO}_{2}$ in the graphene framework.

Reduction of $\mathrm{SnO}_{2}$ to metallic $\mathrm{Sn}$ is also possible in the confined space. Confining Sn in graphene sheet can effectively solve the problem associated with the deterioration of catalytic activity in ultrathin Sn metal on open surface. Xie's group ${ }^{[36]}$ elucidated the successful insertion of Sn quantum sheet in between graphene layers. A temperature programmed calcination of ultrathin $\mathrm{SnO}_{2}$ layers in glucose (carbon source) assisted the spatially confined reduction of $\mathrm{SnO}_{2}$ to $\mathrm{Sn}$ in between layers of graphene. The interplanar spacing of 0.299 and $0.277 \mathrm{~nm}$ in HRTEM image of Figure 4e corroborate the existence of tetragonal Sn encapsulated in graphene sheet. This is a clear demonstration that the oxidation of highly reactive metals can be protected through application of 2D protective layers, making them available for long-term catalysis. As for the vdW gaps in layered transition metal dichalcogenides, confining a catalyst usually involves the prior intercalation by Li ions followed by exchange of the intercalated Li with the desired catalysts, which ultimately directs the catalysts in the vdW gaps. The first intercalation step results in the distortion of lattice and generation of $1 \mathrm{~T}$ phase $\left(1 \mathrm{~T}-\mathrm{Li}_{x} \mathrm{MX}_{2}\right)$ with strong reducing ability to confine zerovalent transition metals. The precious metal, $\mathrm{Pt}$, has been confined in the vdW gaps of $\mathrm{MoS}_{2}$ and demonstrated superior catalytic activity with lower Pt loading. ${ }^{[38]}$ This strategy can also be extended to confine other transition metals such as Ru, Au, $\mathrm{Pd}$, as can be seen from the scheme in Figure 4d. In some cases, the hydrated metal precursors may induce the formation of an alkaline environment during the exchange step due to the slow concomitant reaction of Li with water. ${ }^{[72]}$ This favors the formation of metal hydroxide nanoparticles in the vdW gap instead of zerovalent metals. In either case, the crystalline feature of the host is significantly affected during confinement. Figure $4 \mathrm{f}$ shows the short-range ordering on $\mathrm{MoS}_{2}$ after confinement of $\mathrm{Co}(\mathrm{OH})_{2}$ nanoparticles in the interlayer vdW gaps. The $d$-spacing of the prominent (002) plane in $\mathrm{MoS}_{2}$ owned different spacings (I, II, III, IV, V, and VI). These short-range crystalline features are caused by lithium intercalation and subsequent $\mathrm{Co}^{2+}$ exchange. The exfoliated $\mathrm{MoS}_{2}$ nanosheet without lithium is reported to have a uniform and sharp lattice plane spacing distribution of $0.62 \pm 0.02 \mathrm{~nm}$, while a broader range of lattice spacing $(0.64 \pm 0.20 \mathrm{~nm})$ is present after $\mathrm{Co}(\mathrm{OH})_{2}$ confinement in the vdW gaps of $\mathrm{MoS}_{2}$. In fact, a certain amount of disorder is desirable to maximize the density of active sites and to facilitate electron transfer on the basal planes of $\mathrm{MoS}_{2} \cdot{ }^{[75]}$ A phase transition back from $1 \mathrm{~T}$ to $2 \mathrm{H}$ occurs after $\mathrm{Li}$ ion exchange. The transition metals do not have electron donating role like Li and hence cannot induce phase changes if they are kept in the vdW gaps of TMDs. In general, the layer to layer distance can be tuned from tenths to several nanometers, allowing 

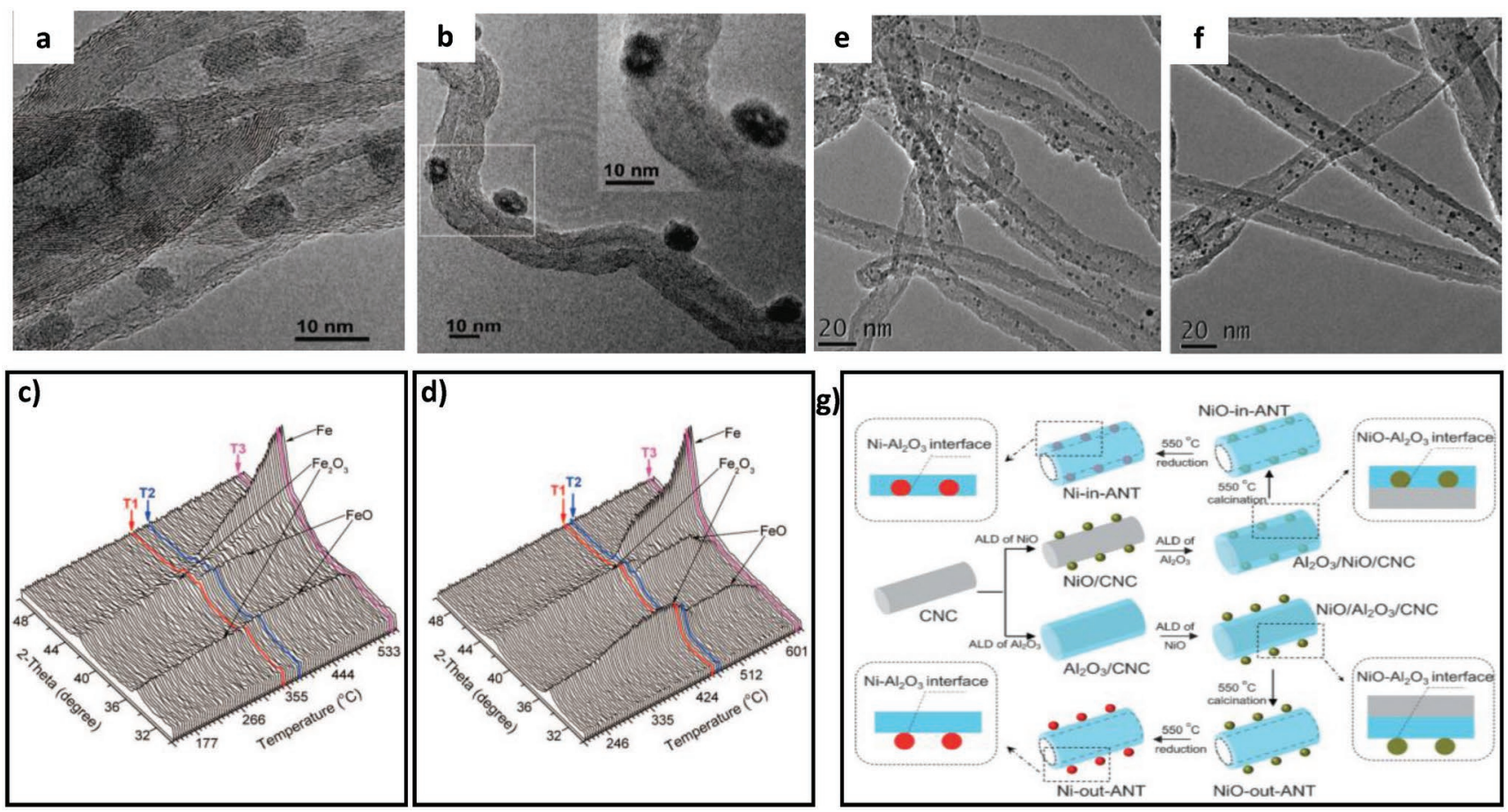

Figure 5. TEM images of the activated Fe confined in a) CNTs and distributed on the exterior surface of b) the CNT. In situ XRD patterns for Fe $\mathrm{O}_{3}$ undergoing a temperature-programmed reduction confined in c) CNT channels and kept on the outside surface of d) the CNT. T1, T2, and T3 represent the temperatures at which $\mathrm{FeO}$ emerges, Fe appears, and $\mathrm{FeO}$ disappears, respectively. Reproduced with permission. ${ }^{[80]}$ Copyright 2008 , American Chemical Society. TEM image of Ru nanoparticles filled in CNT channels via wet chemistry method e) without and f) with ultrasonic treatment and extended stirring. Reproduced with permission. ${ }^{[95]}$ Copyright 2008, The Royal Society of Chemistry. g) Scheme of the template assisted method for filling $\mathrm{Ni}$ nanoparticles in $\mathrm{Al}_{2} \mathrm{O}_{3}$ nanotube. Reproduced with permission. ${ }^{[76]}$ Copyright 2015, Wiley-VCH.

the space to be a convenient platform to confine various active species such as atoms, ions, molecules, etc., and to boost the catalytic activity of the composite system.

\subsection{D Channels (Nanotubes)}

Nanotubes can also be used as scaffolds with well-defined hollow interiors for physical confinement of nano-objects (Figure 1c). Alumina $^{[76]}$ and titania ${ }^{[77]}$ nanotubes were used in the past to confine catalysts in them. However, the most common platform with a 1D channel for confined catalysis are CNTs, ${ }^{[78,79]}$ with tubular shape and variable number of walls (single, double, or multiwall), depending on the number of wrapped layers. Apart from spatial restriction, the reactivity of the confined species is modified by the interaction with the interior wall of the CNT. Bao's group ${ }^{[80,81]}$ has studied the redox properties of iron oxide with and without confinement inside a CNT (Figure 5a-d). They monitored the redox status of $\mathrm{Fe}_{2} \mathrm{O}_{3}$ nanoparticles by in situ $\mathrm{X}$-ray diffraction (XRD) (Figure $5 \mathrm{c}, \mathrm{d}$ ) and the location of the particles (inside/outside the CNT) through transmission electron microscopy (TEM) (Figure 5a,b). With increasing temperature, $\mathrm{Fe}_{2} \mathrm{O}_{3}$ transforms to $\mathrm{FeO}$, then eventually to $\mathrm{Fe}$ in $\mathrm{H}_{2}$ atmosphere. This step-wise phase transformation occurs at lower temperature if confined inside the CNT channel as compared to those attached to the exterior surface $\left(\approx 80-100{ }^{\circ} \mathrm{C}\right.$ lower inside the CNT than outside). The degree of confinement, and hence the extent of alteration of the chemical reaction, greatly depends on the diameter of the confined region, such that the reduction temperature can even be much lower when decreasing the inner diameter of the tube. ${ }^{82]}$

The research effort in this scientific arena is, therefore, devoted to synthesizing smaller tube diameter to realize stronger space confinement due to larger curvature and more distorted $\mathrm{sp}^{2}$ hybridization. ${ }^{[32]}$ In fact, it has been computationally predicted that there is an optimum diameter, beyond which the catalytic activity is negatively affected. ${ }^{[83]}$ If the diameter is too small, the binding energy is extremely weakened and hence it is difficult to activate the catalytic reactions, according to the Sabatier principle. ${ }^{[84]}$ In line with this, the size of the nanoparticles to be confined should also be small enough to be accommodated in the small diameter channel. In addition to the diameter, the length of the CNT is also a determining factor. Several micrometer long channels may induce transport resistance of ions or molecules, which hinders the filling and retards the catalytic reaction. Various methods such as atomic force microscopy (AFM) tips, ${ }^{[85]}$ electron beam, ${ }^{[86]}$ ball milling, ${ }^{[87]}$ oxidation with $\mathrm{Ag}, \mathrm{NiO}$ or mixture of concentrated acid ${ }^{[88]}$ have been adopted so far to cut the long tubes into smaller pieces. As-synthesized CNTs often have closed ends and various impurity residues are left on their surface. Opening the tube and removing such impurities are important prerequisites for filling the desired catalysts into the tube channel and realizing enhanced catalysis. The most common practice is treating the CNTs with concentrated nitric acid, which opens the tube ends and washes impurities away from the surface of CNTs. ${ }^{[89]}$ There are important points to 
be taken into account in an effort to fill the nanotubes with the catalyst to be confined. ${ }^{[89]}$ It was theoretically predicted that open nanotubes may be filled by the surrounding fluids through capillary suction. ${ }^{[90]}$ Experimental observation by P. Majayan and S. Lijima $^{[91]}$ reveals that heating the CNT with liquid lead gave rise to opening of the tube ends and subsequent fillings with molten lead. There should be a pressure difference across the curved meniscus of the liquid in the cavities, which would initiate capillary rise. The insertion of active components inside the tube channel depends on wettability of the substance and capillary forces of the tube. Based on these premises, incipient wetness impregnation method has been employed by many research groups. It involves the insertion of desired metals from their precursor solution into oxidized CNTs by capillarity. ${ }^{\left[{ }^{[2]}\right.}$ In some cases, the metal precursor may percolate into the cavity of the tube and leave part of the nanoparticles on the exterior surface of the CNT (unconfined). ${ }^{[93]}$ These approaches require additional washing steps to remove the metal deposited on the external surfaces. Thus, they suffer from the limitation that significant amount of precursor is lost during the synthesis as only a small fraction of the nanoparticles is inserted into the tube, while the rest are attached on the external surface and are eventually washed out. Ultrasonic treatment and stirring can assist the capillary force to draw the desired components from the solution. ${ }^{[94]}$ Figure 5e shows the TEM image related to an attempt to fill the CNT by Ru particles through simple stirring. On top of nonhomogeneous distribution, there is still considerable amount of $\mathrm{Ru}$ particles attached on the outer surface of the tube. Stirring and ultrasonication significantly assist the capillary action by facilitating the expulsion of air and by allowing the migration of the solution into the tube channel. Moreover, solvents (like acetone, for instance) will evaporate during stirring and sonication, originating a concentration gradient for the precursor of the nanoparticle to diffuse away from the solution toward the tube channel. Thus, after prolonged stirring and ultrasonic treatment, more $\mathrm{Ru}$ particles are introduced into the channel (Figure 5f), demonstrating the effectiveness of extended stirring and ultrasonication in accelerating the filling of open channels. ${ }^{\left[{ }^{[5]}\right.}$ Another method is a multistep, template assisted route. It involves prior synthesis of CNTs inside anodic aluminum oxide membrane, followed by filling the resulting template with the desired nanoparticles and eventually dissolving the aluminum oxide membrane. ${ }^{[96]}$ Template assisted method can also work for filling catalysts in the nanotube channels other than CNTs. The work by $\mathrm{Z}$. Gao et al. ${ }^{[76]}$ deals with entrapping $\mathrm{Ni}$ nanoparticles in the $\mathrm{Al}_{2} \mathrm{O}_{3}$ nanotubes. They employed a carbon nanocoil template, which can be easily removed with low temperature treatments after directing the Ni nanoparticles into the tube channel (Figure $5 \mathrm{~g}$ ). Apart from being confined in the tube channels, the Ni nanoparticles are also entrapped in the cavities of the interior wall of $\mathrm{Al}_{2} \mathrm{O}_{3}$ after the template is removed, ensuring multiple confinement. This route may stimulate the exploration of tubular morphologies beyond CNTs in the quest for enhanced catalysis.

\subsection{OD Pores}

Microporous and mesoporous materials such as zeolites, metal organic frameworks, etc., are convenient platforms to be used as host for a 0D space confinement (Figure 1d). In an effort to synthesize nanosized particles (or even single atoms), these platforms have been employed as a support to prevent uncontrollable particle size sintering/agglomeration, enabling fine tuning of the size and shape of the resulting nanoparticles. This strategy is called confined synthesis, laying a foundation for confined catalysis. ${ }^{[33]}$ Zeolites have drawn the attention of many researchers due to their fascinating physical-chemical features such as well-defined channels, tunable acidity and basicity, high chemical and thermal stability. ${ }^{[97]}$ The pores, into which the diffusion, adsorption, and reactions are facilitated, are selective enough to entrap molecules. ${ }^{[98]}$ While confining the nanoparticle into the particular porous site, one should avoid large and nonuniform nanoparticles as well as poor dispersion (uneven distribution). Various methods such as ion exchange, ${ }^{[99]}$ ligand stabilization, ${ }^{[100]}$ etc., have been employed so far to confine nanoparticles in porous sites. Recently, an in situ approach has been reported ${ }^{[101,102]}$ to confine metal nanoparticles in zeolites directly through the hydrothermal method. Organic additives were used for stabilizing the metal species during zeolite crystallization to prevent the metal aggregation into larger clusters. This route of in situ encapsulation guarantees uniform dispersion of small nanoparticles into the confining region. However, the use of organic additives may still produce metal nanoparticles, whose diameters do not fit the cavity of the zeolite pores. Motivated by this, J. Zhang et al., ${ }^{[103]}$ reported a general approach to confine metal nanoparticles of controlled size into zeolite pores without the use of organic additives. The most important finding in their work was to employ seeds of zeolites containing the metal nanoparticles to be confined. The size of metal nanoparticles on the zeolite seeds can be adjusted. After placing the seed into aluminosilicate or silicate for crystallization of zeolite at the vicinity of the metal-containing seeds, metal nanoparticles with size ranging from 0.8 to $3.6 \mathrm{~nm}$ were obtained. The amorphous aluminosilicate gel entirely covers the metal nanoparticles on the surface of zeolite seed, preventing aggregation during the crystallization process. This route worked for platinum, palladium, rhodium and silver nanoparticles. The case of $\mathrm{Pt}$ is schematically depicted as an instance in Figure 6a, visualizing that the nanoparticles are firmly fixed within the zeolite crystals, as confirmed by scanning transmission electron microscopy (Figure 6d). The pre-seeding step plays a crucial role in confining the metal nanoparticles. Without this step, the process would result in the random attachment of the nanoparticles on external surface of zeolite (Figure 6b,e). It is clear from these results that designing the seeding step for catalysts other than noble metals is important to further develop and exploit this approach.

Another intriguing scaffold for $0 \mathrm{D}$ confinement are the porous sites on different kinds of zeolitic metal azolate frameworks (a subclass of metal organic frameworks, MOFs). MOFs endow strong metal-support interaction between metallic nanoparticles and organic chelates/metal-oxo clusters in the confinement site. ${ }^{[104]}$ These platforms have cage-like pores with continuous and permeable channels, through which reactants and products are easily transported in them. ${ }^{[105]}$ Of particular interests are those containing $\mathrm{Zn}$ ion and 2-methylimidazolate linkers with high content of nitrogen atoms. 
a)
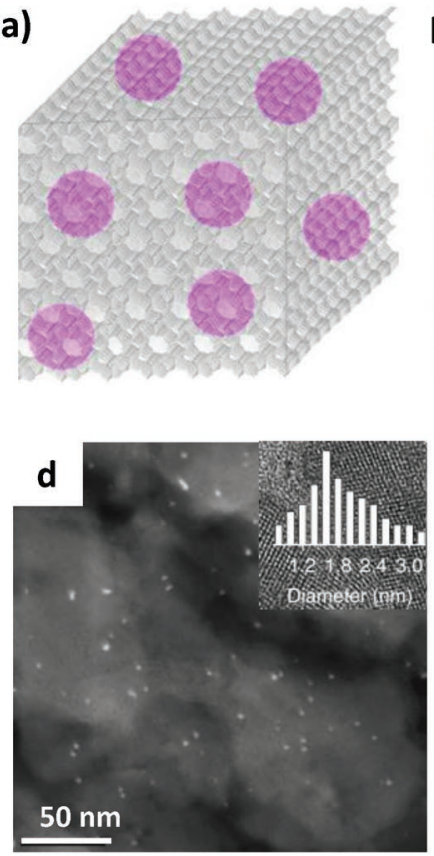

b)
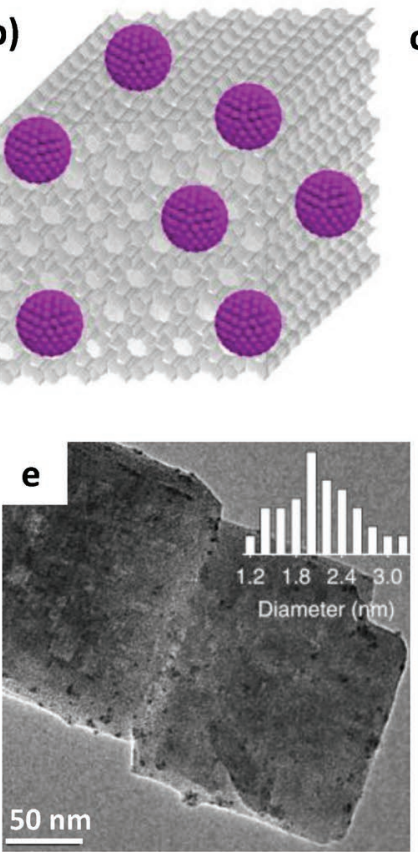

c)
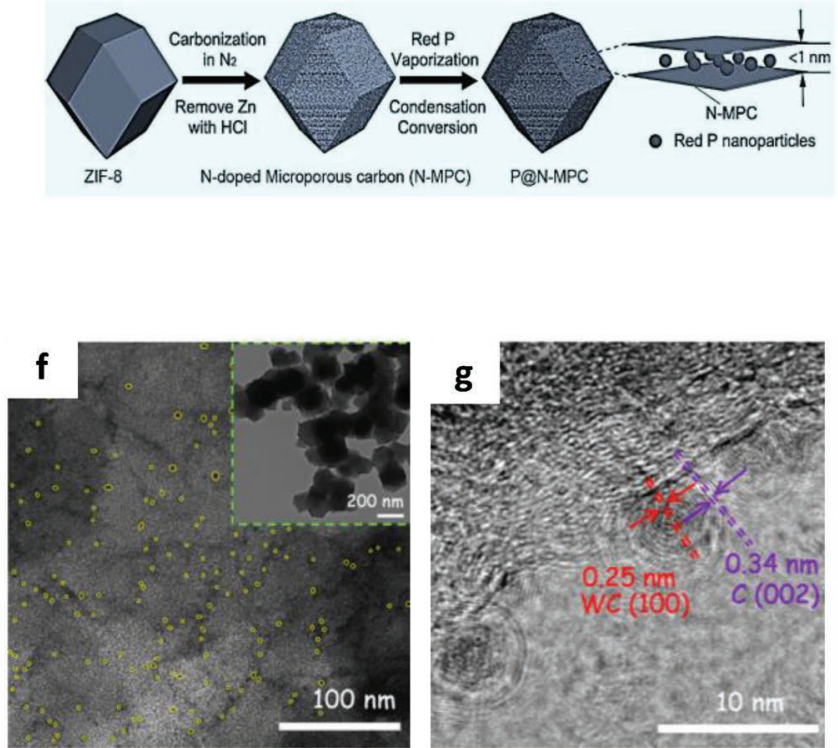

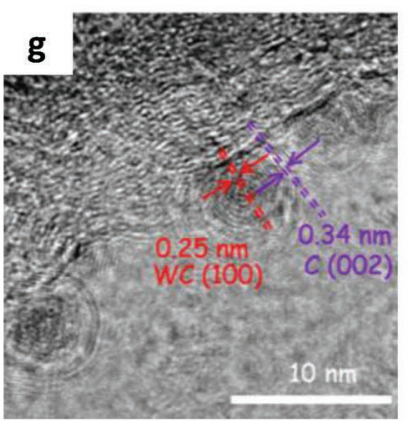

Figure 6. Scheme of the production of a) confined and b) unconfined $\mathrm{Pt}$ in zeolite. c) A procedure for confining red $\mathrm{P}$ in porous sites of zeolite. d,e) TEM images of samples obtained from the (a) and (b) scheme, respectively. The insets report the particle size distributions. f) TEM and g) HRTEM images of ultrasmall WC nanoparticles confined in porous sites of nitrogen-doped nanoporous carbon. a,b,d,e) Reproduced with permission. [103] Copyright 2018, Nature Publishing Group. c) Reproduced with permission. ${ }^{[118]}$ Copyright 2016, Wiley-VCH. f,g) Reproduced with permission. ${ }^{[108]}$ Copyright 2017, American Chemical Society.

Thermal treatment of this composition results in the simultaneous nitrogen doping of the carbon shell that would help stabilizing a small cluster of confined metal nanoparticles. ${ }^{[106,107]}$ Figure $6 \mathrm{c}$ schematically illustrates the route for confinement of red $\mathrm{P}$ in nitrogen-doped carbon framework derived from zeolitic imidazolate framework. Heating at programmed temperature results in carbonizing the framework, and acid treatment eliminates the $\mathrm{Zn}$ content to eventually yield nitrogendoped carbon cages with well-defined pore size $(<1 \mathrm{~nm})$. The red $\mathrm{P}$ can then be vaporized and condensed into the porous sites, and confined there. It is noteworthy that the incoming material to be confined is isolated and incorporated into these sites, in a way that prevents agglomeration and formation of big clusters during thermal treatment. This approach also works for the confinement of metal carbide. Recently, Y. T. Xu and co-workers ${ }^{[108]}$ have successfully confined a very smallsized (2 nm) WC nanoparticles into nitrogen-doped porous carbon derived from zeolitic imidazolate framework. As can be seen in Figure 6f, the ultrasmall WC nanoparticles are homogenously embedded in the nanoporous carbon cage. The host (i.e., the nitrogen-doped graphitic carbon cage) and the guest (WC) are observable from their distinct interplanar spacing (Figure $6 \mathrm{~g}$ ). The advantage in this procedure lies on the isolation of the $\mathrm{W}$ precursor, $\mathrm{W}(\mathrm{CO})_{6}$, within the cage of the MOF. Upon thermal treatment, the precursor releases $\mathrm{W}$ atom inside the cage, which reacts with $\mathrm{C}$ atom from the host framework, eventually resulting in the formation of WC in confined zone. Thus, nitrogen-doped porous carbon frameworks are convenient 0D platforms for confining metal carbides. They can also be derived from in situ polymerization in presence of metal precursor, as has been observed by X. Feng's group. ${ }^{[109]}$ They anchored $\mathrm{Mo}_{4} \mathrm{O}_{13}{ }^{-2}$ as Mo precursors on polyaniline (PANI) sheet, which yields $\mathrm{Mo}_{2} \mathrm{C}$ confined in $\mathrm{N}$-doped porous carbon after pyrolysis. In general, the strategies for $0 \mathrm{D}$ confinement rely on confined synthesis to yield a confined catalyst. Unlike most of the cases in 2D or 1D confinement, where the catalysts are filled in the desired space, OD involves the synthesis of the catalysts in the porous sites or cages and keeping them for undergoing confined catalysis. This helps in realizing ultrasmall nanoparticles with enhanced catalytic activity.

\section{Catalytic Applications}

In connection to the development of active and stable catalysts, various synthesis methods have been developed to expose abundant active sites on the surface. ${ }^{[110]}$ Given the exposed active surfaces, confinement guarantees long-term application of the catalysts, in addition to enhancing their intrinsic activity. The following subsections highlight the progresses so far in applying space confined catalysis for different kinds of reactions.

\subsection{Water Splitting Reactions}

The splitting of a water molecule into its constituent parts leads to the greenest route for powering our planet without the risk of global warming. It comprises HER and oxygen evolution reaction (OER), both of which require specific thermodynamic and kinetic conditions. The fundamentals of HER and OER in 

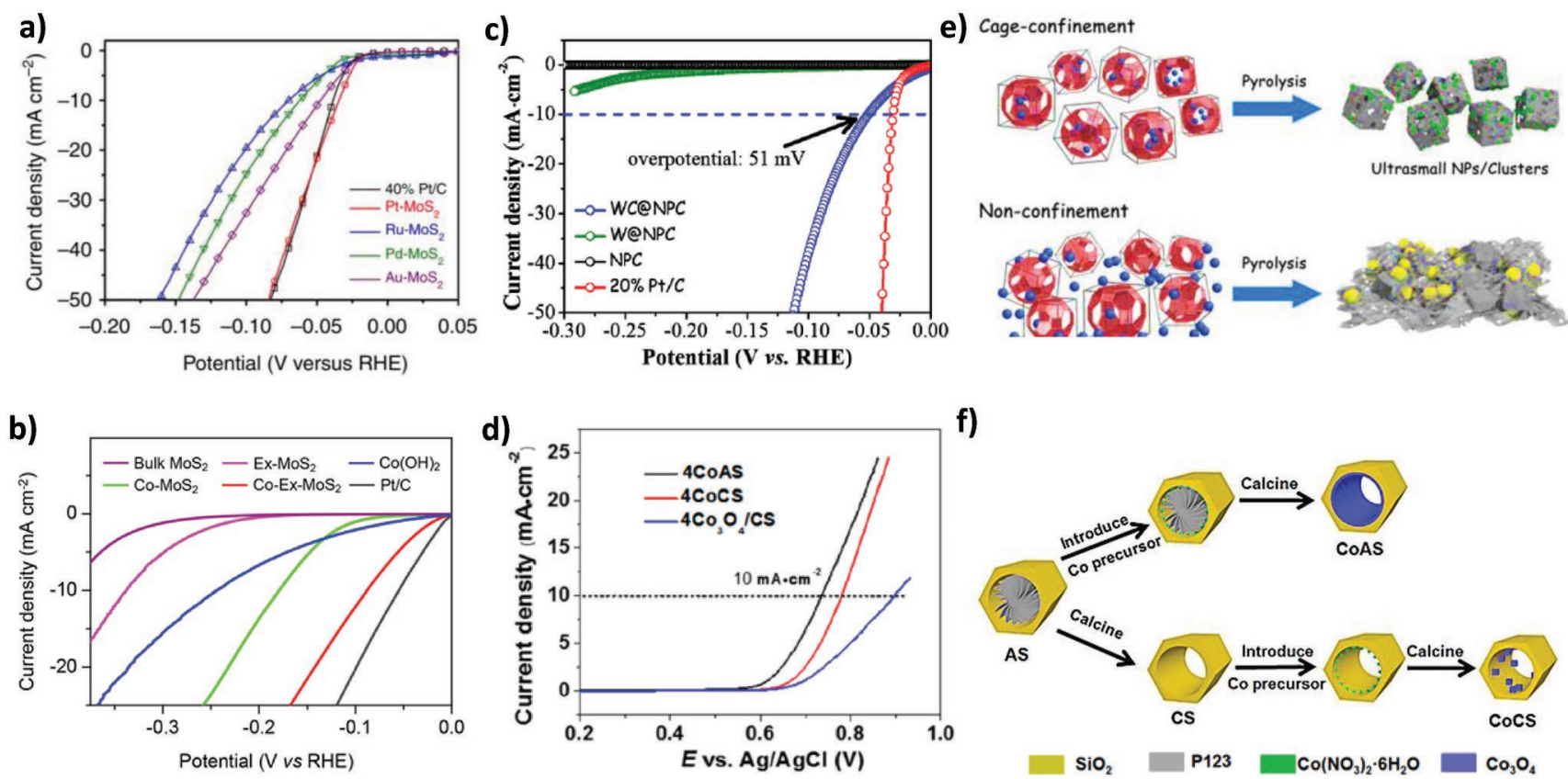

Figure 7. Linear sweep voltammetry curves revealing the catalytic performance of a) various metals confined in vdW gaps of $\mathrm{MoS}_{2}$ for $\mathrm{HER}$ (in $0.5 \mathrm{M}$ $\mathrm{H}_{2} \mathrm{SO}_{4}$ ); b) $\mathrm{Co}(\mathrm{OH})_{2}$ nanoparticles confined in $\mathrm{MoS}_{2}$ for HER in $1.0 \mathrm{M} \mathrm{KOH}\left(\mathrm{Co}-E x-\mathrm{MoS}_{2}\right.$ and Co-MoS 2 denote exfoliated $\mathrm{MoS}_{2}$ nanosheets and bulk $\mathrm{MoS}_{2}$ were used as a platform for confinement respectively); c) WC nanoparticles confined in nitrogen-doped nanoporous carbon cage (NPC) for HER in $0.5 \mathrm{M} \mathrm{H}_{2} \mathrm{SO}_{4}$, where W@NPC denotes non confined W cluster on the surface of NPC; d) $\mathrm{Co}_{3} \mathrm{O}_{4}$ confined in porous silica for OER in $0.1 \mathrm{~m} \mathrm{KOH}$. Schemes in (e) and ( $\mathrm{f}$ ) depict the confinement routes of catalysts, whose performances are presented in (c) and (d), respectively. a) Reproduced with permission. ${ }^{[38]}$ Copyright 2017, Nature Publishing Group. b) Reproduced with permission. ${ }^{[72]}$ Copyright 2018, American Chemical Society. c,e) Reproduced with permission. ${ }^{108]}$ Copyright 2017, American Chemical Society. d,f) Reproduced with permission. ${ }^{[13]}$ Copyright 2019, American Chemical Society.

different $\mathrm{pH}$ solutions are well-documented.[111] We will here review the recent progresses made so far in confining catalysts in various platforms to boost the catalytic activities for HER and OER. The HER counterpart can be considered as a model reaction for confined systems owing to the small hydrated radius and fast diffusion kinetics of $\mathrm{H}^{+}$. Many attempts have been made so far in confining a catalyst to enhance its performance. ${ }^{[38,72,73,108,112,113]}$ In this regard, the work of Z. Chen et al. ${ }^{[38]}$ illustrates the general approach (Figure $4 \mathrm{~d}$ ) to confine zerovalent metals in vdW gaps of layered $2 \mathrm{D} \mathrm{MoS}$ and elucidates their enhanced electro catalytic activities toward HER in $0.5 \mathrm{M} \mathrm{H}_{2} \mathrm{SO}_{4}$ solution. Figure 7a reports the linear sweep voltammetry curves for $\mathrm{Pt}, \mathrm{Ru}, \mathrm{Pd}$, Au confined in vdW gaps of $\mathrm{MoS}_{2}$. As compared to the $40 \%$ commercial Pt/C, Pt in $\mathrm{MoS}_{2}$ (the content of $\mathrm{Pt}$ is $10.4 \%$ ) performs almost equally, but with significantly enhanced stability. The activity of commercial Pt/C diminishes after stability test owing to the dissociation/aggregation of Pt nanoparticles and corrosion of the carbon support. Space confinement solves this problem. The issue of stability is of particular importance in designing efficient HER catalysts in alkaline electrolytes. Motivated by this, B. Liu's ${ }^{[72]}$ group has confined earth abundant $\mathrm{Co}(\mathrm{OH})_{2}$ nanoparticles in vdW gaps of $\mathrm{MoS}_{2}$ and realized superior HER performance $(89 \mathrm{mV}$ overpotential at a current density of $10 \mathrm{~mA} \mathrm{~cm}{ }^{-2}$ and Tafel slope of $53 \mathrm{mV} \mathrm{dec}^{-1}$ ) in $1 \mathrm{M} \mathrm{KOH}$ solution with excellent stability. The unconfined $\mathrm{Co}(\mathrm{OH})_{2}$ generates $\mathrm{H}_{2}$ with relatively sluggish kinetics (Tafel slope of $124 \mathrm{mV} \mathrm{dec}{ }^{-1}$ ) and requires $240 \mathrm{mV}$ to achieve a current density of $10 \mathrm{~mA} \mathrm{~cm}{ }^{-2}$. Such a significantly improved activity is evident in Figure $7 \mathrm{~b}$ for $\mathrm{Co}(\mathrm{OH})_{2}$ confined in vdW gaps of $\mathrm{MoS}_{2}$ as compared to bare $\mathrm{Co}(\mathrm{OH})_{2}$ and bare $\mathrm{MoS}_{2}$, further verifying the pivotal role of space confinement in enhancing catalytic activity. The confined $\mathrm{Co}(\mathrm{OH})_{2}$ nanoparticles accelerate the kinetics of water dissociation and the $\mathrm{MoS}_{2}$ edges speed up the kinetics of hydrogen generation, conjointly enhancing the overall performance.

In addition to the 2D hosts, $0 \mathrm{D}$ pores are extremely interesting in relation to the catalysis of water splitting reactions. As mentioned in section 2.3, the confined synthesis is vital to realize ultrasmall nanoparticles to be confined in porous sites that exhibit superb activity. In the work of Y. T. Xu et al.,[108] the confined synthesis led to the confinement of WC nanoparticles in nanopores of carbon cage and demonstrates an excellent performance toward HER in $0.5 \mathrm{M} \mathrm{H}_{2} \mathrm{SO}_{4}$, requiring only $51 \mathrm{mV}$ to obtain a current density of $10 \mathrm{~mA} \mathrm{~cm}{ }^{-2}$ and a Tafel slope of $49 \mathrm{mV} \mathrm{dec}{ }^{-1}$. However, their conventional synthesis results in the formation of aggregates and in the sintering of larger metal particles, with lower catalytic activity (Figure $7 \mathrm{c}, \mathrm{e}$ ). The same trend has also been observed in confining $\mathrm{Co}_{3} \mathrm{O}_{4}$ in porous sites of mesoporous silica. ${ }^{[113]}$ The confined $\mathrm{Co}_{3} \mathrm{O}_{4}$ nanoparticles exhibited higher catalytic activity toward OER as compared to conventionally synthesized mere mixture of $\mathrm{Co}_{3} \mathrm{O}_{4}$ and silica (Figure 7d,f). As shown in Figure 7d, unconfined $\mathrm{Co}_{3} \mathrm{O}_{4}$ requires an overpotential of $0.9 \mathrm{~V}$ to achieve a current density of $10 \mathrm{~mA} \mathrm{~cm}{ }^{-2}$ in OER. Confining the $\mathrm{Co}_{3} \mathrm{O}_{4}$ catalysts reduces this overpotential to $0.73 \mathrm{~V}$, substantiating the pivotal role of confinement. Moreover, the employed template, along with the hydroxy group ( $\mathrm{Si}-\mathrm{OH})$ at silica surface, improved the dispersibility of $\mathrm{Co}_{3} \mathrm{O}_{4}$ in porous sites, ensuring long-term catalysis 

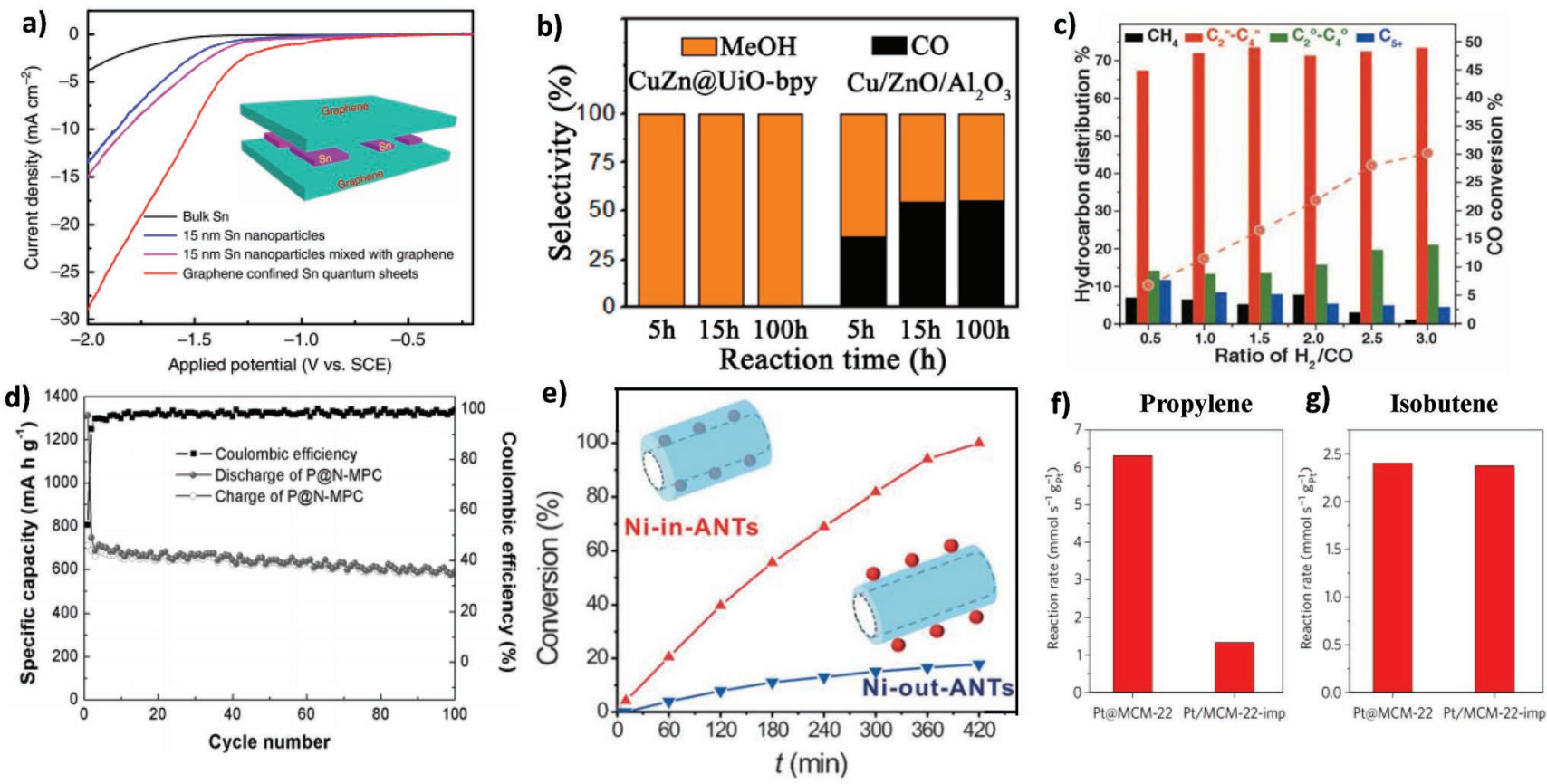

Figure 8. a) Linear sweep voltammetry curves revealing the $\mathrm{CO}_{2}$ reduction performance of $\mathrm{Sn}$ nanosheets confined in layers of graphene and other samples for comparison, in $0.1 \mathrm{M} \mathrm{NaHCO}_{3}$ aqueous solution. The inset depicts the scheme of confinement. Reproduced with permission. ${ }^{[36]}$ Copyright 2016, Nature Publishing Group. b) Selectivity of $\mathrm{Cu} / \mathrm{ZnO}_{x}$ nanoparticles confined in the pores of Metal-Organic Frameworks for $\mathrm{CH}_{3} \mathrm{OH}$ synthesis over CO. Reproduced with permission. ${ }^{[104]}$ Copyright 2017, American Chemical Society. c) CO conversion and product distribution at different $\mathrm{H}_{2} /$ $\mathrm{CO}$ ratios by partially reduced $\mathrm{ZnCrO}_{x}$ and confined acidic pores of zeolite. Reproduced with permission. ${ }^{[117]}$ Copyright 2017, American Association of Advancement of Science. d) Electrochemical performance of red P confined in the pores of zeolitic imidazolate framework for sodium ion battery. Reproduced with permission. ${ }^{[118]}$ Copyright 2017, WILEY-VCH. (e) Comparison of confined and unconfined Ni nanoparticles toward selective hydrogenation of cinnamaldehyde. Reproduced with permission. ${ }^{[76]}$ Copyright 2015, WILEY-VCH. Comparison of the reaction rates of Pt confined in pores of zeolite (Pt@MCM-22) and Pt impregnated on zeolite (Pt/MCM-22-imp) toward hydrogenation of f) propylene and g) isobutene. Reproduced with permission. ${ }^{[39]}$ Copyright 2017, Springer.

with enhanced activity. The performance enhancement can be associated to the well-ordered assembly of the catalysts into the confined space, demonstrating once again that space confinement is an appealing strategy to boost the performance of water splitting catalysts.

\section{2. $\mathrm{CO}_{2}$ Reduction/Syngas Conversion}

Carbon dioxide is not a benign component to the environment. In our technological Era, its concentration in the atmosphere has reached unprecedented levels and continues to rise due to the combustion of fossil fuels. The reduction of $\mathrm{CO}_{2}$ is challenging as it requires multistep reactions with more than one electron involved. ${ }^{[14]}$ Various products (such as $\mathrm{CH}_{4}, \mathrm{CH}_{3} \mathrm{OH}$, $\mathrm{C}_{2} \mathrm{H}_{5} \mathrm{OH}$, etc.) are expected in the reduction process demanding stringent selectivity of the catalyst toward the desired product. Different strategies have been explored to control selectivity, to reduce overpotentials, and to increase energy efficiency. ${ }^{[115]}$ Recently, space confinement has become a frontier tool for the purpose. It plays a pivotal role in assisting the conversion of $\mathrm{CO}_{2}$ into valuable organic compounds by providing larger number of under coordinated active sites that do not deteriorate through time. ${ }^{[36,104]}$ The $\mathrm{CO}_{2}$ reduction ability of Sn quantum sheets confined between the layers of graphene is illustrated in Figure 8a. It is evident that there is a significant improvement in performance as compared to the one kept in open surface and other control samples. ${ }^{[36]}$ A current density of $21.1 \mathrm{~mA} \mathrm{~cm}^{-2}$ is recorded at a potential of $1.8 \mathrm{~V}$ versus saturated calomel electrode (SCE) in the case of confined Sn in graphene layers. The unconfined $\mathrm{Sn}$ on graphene surface, instead, requires $\approx 3.6 \mathrm{~V}$ versus SCE to achieve the same current density. The comparison of the Faradaic efficiency and of the Tafel slope corroborate the conclusion that the confined catalyst performs with higher Faradaic efficiency (1.45 times higher) and improved kinetics (83 vs $150 \mathrm{mV} \mathrm{dec}^{-1}$ ), compared to the unconfined system. The enhanced performance can be associated to inhibition of the oxidation processes for confined Sn thin sheets, and to a higher electrochemical active surface, with maximized exposure of active sites for catalysis. Industrial scale reduction of $\mathrm{CO}_{2}$ (methanol synthesis) can be obtained through the ternary $\mathrm{Cu} / \mathrm{ZnO}_{x} / \mathrm{Al}_{2} \mathrm{O}_{3}$ catalyst. ${ }^{[16]}$ In this system, the critical role of the interface between $\mathrm{Cu}$ and $\mathrm{ZnO}_{x}$ is believed to contribute to the creation of active sites. The grand challenge, however, is to inhibit the aggregation of the $\mathrm{Cu}$ nanoparticles through time, which separate from the $\mathrm{ZnO}_{x}$ part, eventually degrading the interface properties. This leaves the $\mathrm{Cu}$ surface un-interfaced, which results in the production of $\mathrm{CO}$ rather than $\mathrm{CH}_{3} \mathrm{OH}$. Confinement has been employed as a substantial tool to solve the problems associated with interface degradation and hence selectivity issues. ${ }^{[104,117]}$ Figure $8 \mathrm{~b}$ illustrates the result obtained upon confining $\mathrm{Cu} / \mathrm{ZnO}_{x}$ matrix in $\mathrm{Zr}$ based MOF. As 
compared to $\mathrm{Al}_{2} \mathrm{O}_{3}$ support, the $\mathrm{Zr}$ containing MOF interacts more strongly with $\mathrm{Cu}$, leading to more dispersed nanoparticles and intimate contact with the $\mathrm{ZnO}_{x}$. Hence, the space confinement helps the interface persisting longer, guaranteeing good selectively for $\mathrm{CH}_{3} \mathrm{OH}$ over $\mathrm{CO}$ production. Obtaining multi carbon products $(\mathrm{C} 2+)$ from $\mathrm{CO}_{2}$ reduction is highly desirable. This requires careful design of catalysts that favor $\mathrm{C}-\mathrm{C}$ coupling instead of hydrogenation or methanation. In this regard, successful selectivity toward $\mathrm{C} 2+$ product was investigated by $\mathrm{F}$. Jiao's group ${ }^{[17]}$ through directing the $\mathrm{C}-\mathrm{C}$ coupling reaction in confined zone. They reported a catalyst consisting of partially reduced mixed metal oxide, $\mathrm{ZnCrO}_{x}$, and mesoporous zeolite with acidic pores. Uncontrollable hydrogenation is prevented in such a way that the $\mathrm{ZnCrO}_{x}$ activates the $\mathrm{CO}$ and $\mathrm{H}_{2}$, and the $\mathrm{C}-\mathrm{C}$ coupling takes place in the confined zeolitic pores. As shown in Figure 8c, the conversion of $\mathrm{CO}$ and selective production of $\mathrm{C} 2+$ organic compounds are realized from the catalyst system containing $\mathrm{ZnCrO}_{x}$, and mesoporous zeolite. The porous sites in zeolite play a crucial role in assisting $\mathrm{C}-\mathrm{C}$ coupling reactions. Thus, the issue of selectivity, which is the most serious concern in $\mathrm{CO}_{2}$ reduction technology, can be solved by carefully designing space confined catalytic systems.

\subsection{Other Reactions}

Confined catalysis also finds substantial applications in reactions other than the ones mentioned above. Owing to the enhanced activity, selectivity and stability, this concept has been employed in energy storage devices, ${ }^{[118]}$ and also acknowledged for accelerating reactions such as the hydrogenation of various organic compounds ${ }^{[76,119]}$ and oxidation of CO. ${ }^{[45,46]}$ As an anode material, the critical role of confined phosphorus in OD pores of zeolitic imidazolate framework- 8 has been reported ${ }^{[118]}$ to exhibit long-term sodiation-desodiation cycling in sodium ion battery. The electrolytes can diffuse very rapidly in the pores where the red $\mathrm{P}$ is encapsulated, giving rise to enhanced conductivity and hence electrochemical performance. This setup exhibited a highly reversible specific capacity of $\approx 600 \mathrm{~mA} \mathrm{~h} \mathrm{~g}^{-1}$ at $0.15 \mathrm{~A} \mathrm{~g}^{-1}$ with almost $100 \%$ Coulombic efficiency and negligible fading in cycling (Figure 8d). It is important to note that the confining host buffers the volume change of red $\mathrm{P}$ during repeated cycling, which was a grand problem in unconfined red P observed in other reports. ${ }^{[120]}$

Another important sector, where space confinement got widespread application, is in the hydrogenation of organic compounds. Figure 8e illustrates the significantly improved cinnamaldehyde hydrogenation by Ni nanoparticles confined inside the nanotube channel of $\mathrm{Al}_{2} \mathrm{O}_{3}$. Nearly $100 \%$ conversion was obtained within $7 \mathrm{~h}$ reaction in the case of space confinement, by far exceeding the unconfined Ni nanoparticles. In fact, the size of the confining cavity should be able to accommodate the incoming organic compounds, realizing the positive effect of space confinement, and enhancing the activity. As reported by A. Corma's group, ${ }^{[39]}$ sub-nanometric Pt species (single atoms and clusters) confined within purely siliceous zeolite demonstrated improved performance in hydrogenation of propylene as compared to Pt impregnated on the surface of zeolite (Figure $8 \mathrm{f}$ ). For isobutene, this enhancement does not hold due to the molecular sieving effect (Figure $8 \mathrm{~g}$ ). The catalysis in this case can only be attributable to those Pt species on the external cups of zeolites and hence the effect of confinement is ruled out. This give rise to size-selective hydrogenation of alkene: bigger molecules, in fact, would not be accessible to the confined catalysts. In another report, ${ }^{[48]}$ computational studies on confined and open systems reveal that the $\mathrm{CO}-\mathrm{CO}$ coupling reaction is indeed suppressed in the case of confinement. It has been revealed that the $E_{\text {con }}$ obtained in spaces under graphene for ${ }^{*} \mathrm{CO}(0.45 \mathrm{eV})$ is significantly larger than ${ }^{*} \mathrm{H}(0.1 \mathrm{eV})$, further supporting the importance of size matching. Upon proper design of the confining platform, this strategy can serve as an indispensable tool to accelerate various kinds of chemical reactions.

\section{Conclusions and Prospects}

Space confinement affects the physics and chemistry of the adsorbates/reaction intermediates because of the geometric constraints and the confinement field. Various confinement modes, such as spaces under 2D materials, vdW gaps between layers in 2D materials, and 0D pores in porous materials have been investigated so far as convenient platforms for confining a catalyst. Optimum design of catalysts in these platforms endows enormous potential in the next-generation catalysis. The molecular adsorption on catalysts can be tuned by altering the type of confinement, and the structure and composition of the scaffold. The confined zone provides an excellent opportunity to undergo selective catalysis as some molecules diffuse in the confined zone more easily than others do. In addition to ensuring selectivity, superior stability is also expected in confined systems, owing to the fact that the catalyst is prevented from surface deterioration and particle aggregation. The experimental validation of phenomena speculated only theoretically is critically important. The rational design of Ni nanoparticles covered by graphene was theoretically demonstrated to be crucial to obtain superior electrocatalytic performance of HER from Earth abundant materials. The same design for $\mathrm{Cu}$ and its alloys was proved promising for enhanced $\mathrm{CO}_{2}$ reduction with superb selectivity. Another outstanding example is g- $\mathrm{C}_{3} \mathrm{~N}_{4}$ : it has inherent triangular pores formed by six edge nitrogen atoms, which can serve as favorable sites for the intercalation of adsorbates. The spaces under $\mathrm{g}-\mathrm{C}_{3} \mathrm{~N}_{4}$ are vital for confining catalysts. Confining catalysts in vdW gaps has been studied by applying graphene and TMDs as layered materials. In principle, this can be extended to other types of layered materials such as transition metal phosphorus trichalcogenides, MXenes, black phosphorus, etc. Particularly, newly emerging layered materials known as transition metal phosphorus trichalcogenides have been proposed as promising catalysts in energy conversion reactions. They have wider vdW gaps as compared to both graphene and TMDs. It is, therefore, envisioned that these materials can be convenient platforms to confine diversified groups of catalysts. Future interest may also lie on materials possessing multiple confinement platforms, like graphene aerogels with high surface area and interconnected porosity. They could guarantee multiple confinements of catalysts owing to their $0 \mathrm{D}$ (porosity) and 2D features. The choice of materials 
to be confined should be conducted based on activity, durability, and robustness to allow the realization of desired performances (i.e., bifunctional catalysis in overall water splitting reactions and $\mathrm{C} 2+$ products in $\mathrm{CO}_{2}$ reduction). The functional properties recently recorded from Earth abundant materials, having comparable performance with those of benchmarking precious metals, would find a more fascinating scenario under confinement with a transformational vision in the field of catalysis. This strategy, however, suffers from challenges in developing facile and controllable technique to directly place the catalysts in the confined space. More attention should be devoted to the rational design of synthesis techniques to confine catalysts. Future work should also focus on gaining further insight into the identification of active sites and the mechanism of confined catalysis. Theoretical calculations and in situ characterization techniques are indispensable tools to probe the confining phenomena and mechanism of catalysis. We believe that with facile synthesis, adequate characterization and in-depth mechanism study, confined catalysis could find a significant part in the next-generation catalytic systems for various reactions.

\section{Acknowledgements}

The authors acknowledge the Kempe Foundation (JCK1505, JCK1703, SMK1839), the Knut och Alice Wallenberg Foundation (grant number KAW 2016.346), the ÅFORSK Foundation, and the Luleå University of Technology for financial support.

\section{Conflict of Interest}

The authors declare no conflict of interest.

\section{Keywords}

$\mathrm{CO}_{2}$ reduction, confined catalysis, pore filling, van der Waals gaps, water splitting

Received: July 16, 2019

Revised: August 9, 2019

Published online: September 9, 2019

[1] M. Balat, H. Balat, Energy Sources, Part A 2009, 31, 1280.

[2] H. S. Boudet, Nat. Energy 2019, 4, 446.

[3] D. Deng, K. Novoselov, Q. Fu, N. Zheng, Z. Tian, X. Bao, Nat. Commun. 2016, 11, 218.

[4] J. Qi, W. Zhang, R. Cao, Adv. Energy Mater. 2018, 8, 1701620.

[5] Y. Kuang, G. Feng, P. Li, Y. Bi, Y. Li, X. Sun, Angew. Chem., Int. Ed. 2016, 55, 693

[6] J. Zhang, T. Wang, P. Liu, Z. Liao, S. Liu, X. Zhuang, M. Chen, E. Zschech, X. Feng, Nat. Commun. 2017, 8, 15437.

[7] I. Concina, Z. H. Ibupoto, A. Vomiero, Adv. Energy Mater. 2017, 7, 1770138.

[8] Y. Zhu, X. Liu, S. Jin, H. Chen, W. Lee, M. Liu, Y. Chen, J. Mater. Chem. A 2019, 7, 5875.

[9] F. Wang, T. A. Shifa, X. Zhan, Y. Huang, K. Liu, Z. Cheng, C. Jiang, J. He, Nanoscale 2015, 7, 19764.

[10] B. Gao, X. Li, K. Ding, C. Huang, Q. Li, P. K. Chu, K. Huo, J. Mater. Chem. A 2019, 7, 14.
[11] Y. Shi, B. Zhang, Chem. Soc. Rev. 2016, 45, 1529.

[12] Q. Gao, W. Zhang, Z. Shi, L. Yang, Y. Tang, Adv. Mater. 2019, 31, 1970009.

[13] C. Hu, L. Dai, Adv. Mater. 2017, 29, 1604942.

[14] X. Liu, L. Dai, Nat. Rev. Mater. 2016, 1, 16064.

[15] R. Mazzaro, S. Boscolo Bibi, M. Natali, G. Bergamini, V. Morandi, P. Ceroni, A. Vomiero, Nano Energy 2019, 61, 36.

[16] Y.-R. Zheng, P. Wu, M.-R. Gao, X.-L. Zhang, F.-Y. Gao, H.-X. Ju, R. Wu, Q. Gao, R. You, W.-X. Huang, S.-J. Liu, S.-W. Hu, J. Zhu, Z. Li, S.-H. Yu, Nat. Commun. 2018, 9, 2533.

[17] T. A. Shifa, F. Wang, Y. Liu, J. He, Adv. Mater. 2018, 1804828.

[18] Z. H. Ibupoto, A. Tahira, P. Tang, X. Liu, J. R. Morante, M. Fahlman, J. Arbiol, M. Vagin, A. Vomiero, Adv. Funct. Mater. 2019, 29, 1807562.

[19] A. Tahira, Z. H. Ibupoto, R. Mazzaro, S. You, V. Morandi, M. M. Natile, M. Vagin, A. Vomiero, ACS Appl. Energy Mater. 2019, 2, 2053.

[20] G. Ye, Y. Gong, J. Lin, B. Li, Y. He, S. T. Pantelides, W. Zhou, R. Vajtai, P. M. Ajayan, Nano Lett. 2016, 16, 1097.

[21] J. Leduc, Y. Goenuellue, P. Ghamgosar, S. You, J. Mouzon, H. Choi, A. Vomiero, M. Grosch, S. Mathur, ACS Appl. Nano Mater. 2019, 2, 334.

[22] Y. Yu, G.-H. Nam, Q. He, X.-J. Wu, K. Zhang, Z. Yang, J. Chen, Q. Ma, M. Zhao, Z. Liu, F.-R. Ran, X. Wang, H. Li, X. Huang, B. Li, Q. Xiong, Q. Zhang, Z. Liu, L. Gu, Y. Du, W. Huang, H. Zhang, Nat. Chem. 2018, 10, 638.

[23] M. Chhowalla, H. S. Shin, G. Eda, L.-J. Li, K. P. Loh, H. Zhang, Nat. Chem. 2013, 5, 263.

[24] R. B. Levy, M. Boudart, Science 1973, 181, 547.

[25] J. G. Chen, Chem. Rev. 1996, 96, 1477.

[26] P. Liu, J. A. Rodriguez, J. Am. Chem. Soc. 2005, 127, 14871.

[27] S. H. Petrosko, R. Johnson, H. White, C. A. Mirkin, J. Am. Chem. Soc. 2016, 138, 7443.

[28] J. Mittal, R. B. Best, Proc. Natl. Acad. Sci. USA 2008, 105, 20233.

[29] Q. Fu, X. Bao, Chem. Soc. Rev. 2017, 46, 1842.

[30] V. Mouarrawis, R. Plessius, J. I. van der Vlugt, J. N. H. Reek, Front. Chem. 2018, 6, 623.

[31] V. Augustyn, Y. Gogotsi, Joule 2017, 1, 443.

[32] X. Pan, X. Bao, Acc. Chem. Res. 2011, 44, 553.

[33] Z. Li, X. Zhang, H. Cheng, J. Liu, M. Shao, M. Wei, D. G. Evans, H. Zhang, X. Duan, Adv. Energy Mater. 2019, 1900486.

[34] J. Knossalla, P. Paciok, D. Göhl, D. Jalalpoor, E. Pizzutilo, A. M. Mingers, M. Heggen, R. E. Dunin-Borkowski, K. J. J. Mayrhofer, F. Schüth, M. Ledendecker, J. Am. Chem. Soc. 2018, 140, 15684.

[35] Z.-Y. Zhou, N. Tian, J.-T. Li, I. Broadwell, S.-G. Sun, Chem. Soc. Rev. $2011,40,4167$.

[36] F. Lei, W. Liu, Y. Sun, J. Xu, K. Liu, L. Liang, T. Yao, B. Pan, S. Wei, Y. Xie, Nat. Commun. 2016, 7, 12697.

[37] R. Breslow, Acc. Chem. Res. 1995, 28, 146.

[38] Z. Chen, K. Leng, X. Zhao, S. Malkhandi, W. Tang, B. Tian, L. Dong, L. Zheng, M. Lin, B. S. Yeo, K. P. Loh, Nat. Commun. 2017, 8, 14548.

[39] L. Liu, U. Díaz, R. Arenal, G. Agostini, P. Concepción, A. Corma, Nat. Mater. 2017, 16, 132.

[40] S. Roy, A. Rao, G. Devatha, P. P. Pillai, ACS Catal. 2017, 7, 7141.

[41] J. Xiao, X. Pan, S. Guo, P. Ren, X. Bao, J. Am. Chem. Soc. 2015, 137, 477.

[42] J. M. Martínez de la Hoz, P. B. Balbuena, J. Phys. Chem. C 2011, 115, 21324.

[43] G. E. Ramirez-Caballero, P. B. Balbuena, J. Phys. Chem. C 2009, 113,7851

[44] H. Li, J. Xiao, Q. Fu, X. Bao, Proc. Natl. Acad. Sci. USA 2017, 114, 5930.

[45] Y. Yao, Q. Fu, Y. Y. Zhang, X. Weng, H. Li, M. Chen, L. Jin, A. Dong, R. Mu, P. Jiang, L. Liu, H. Bluhm, Z. Liu, S. B. Zhang, X. Bao, Proc. Natl. Acad. Sci. USA 2014, 111, 17023. 
[46] Y. Zhang, X. Weng, H. Li, H. Li, M. Wei, J. Xiao, Z. Liu, M. Chen, Q. Fu, X. Bao, Nano Lett. 2015, 15, 3616.

[47] Y. Zhou, W. Chen, P. Cui, J. Zeng, Z. Lin, E. Kaxiras, Z. Zhang, Nano Lett. 2016, 16, 6058

[48] H. Li, C. Guo, Q. Fu, J. Xiao, J. Phys. Chem. Lett. 2019, 10, 533.

[49] K. S. Novoselov, A. K. Geim, S. V Morozov, D. Jiang, Y. Zhang, S. V Dubonos, I. V Grigorieva, A. A. Firsov, Science 2004, 306, 666.

[50] G. R. Bhimanapati, Z. Lin, V. Meunier, Y. Jung, J. Cha, S. Das, D. Xiao, Y. Son, M. S. Strano, V. R. Cooper, L. Liang, S. G. Louie, E. Ringe, W. Zhou, S. S. Kim, R. R. Naik, B. G. Sumpter H. Terrones, F. Xia, Y. Wang, J. Zhu, D. Akinwande, N. Alem, J. A. Schuller, R. E. Schaak, M. Terrones, J. A. Robinson, ACS Nano 2015, 9, 11509 .

[51] N. Mounet, M. Gibertini, P. Schwaller, D. Campi, A. Merkys, A. Marrazzo, T. Sohier, I. E. Castelli, A. Cepellotti, G. Pizzi, N. Marzari, Nat. Nanotechnol. 2018, 13, 246.

[52] S. Cao, J. Yu, J. Phys. Chem. Lett. 2014, 5, 2101.

[53] M. Hu, Z. Yao, X. Wang, Ind. Eng. Chem. Res. 2017, 56, 3477.

[54] M. Asadi, K. Kim, C. Liu, A. V. Addepalli, P. Abbasi, P. Yasaei, P. Phillips, A. Behranginia, J. M. Cerrato, R. Haasch, P. Zapol, B. Kumar, R. F. Klie, J. Abiade, L. A. Curtiss, A. Salehi-Khojin, Science 2016, 353, 467.

[55] R. N. Jenjeti, M. P. Austeria, S. Sampath, ChemElectroChem 2016 3,1392

[56] T. A. Shifa, F. Wang, Z. Cheng, P. He, Y. Liu, C. Jiang, Z. Wang, J. He, Adv. Funct. Mater. 2018, 28, 1800548.

[57] F. Wang, T. A. Shifa, P. He, Z. Cheng, J. Chu, Y. Liu, Z. Wang, F. Wang, Y. Wen, L. Liang, J. He, Nano Energy 2017, 40, 673.

[58] Z. Cheng, T. A. Shifa, F. Wang, Y. Gao, P. He, K. Zhang, C. Jiang, Q. Liu, J. He, Adv. Mater. 2018, 30, 1707433.

[59] Y. Wang, J. Mao, X. Meng, L. Yu, D. Deng, X. Bao, Chem. Rev. 2019, 119, 1806

[60] W. Chen, E. J. G. Santos, W. Zhu, E. Kaxiras, Z. Zhang, Nano Lett. 2013, 13, 509.

[61] J. Wintterlin, M. L. Bocquet, Surf. Sci. 2009, 603, 1841.

[62] L. Ferrighi, M. Datteo, G. Fazio, C. Di Valentin, J. Am. Chem. Soc. 2016, 138, 7365.

[63] R. Mu, Q. Fu, L. Jin, L. Yu, G. Fang, D. Tan, X. Bao, Angew. Chem., Int. Ed. 2012, 51, 4856.

[64] F. Tao, S. Dag, L.-W. Wang, Z. Liu, D. R. Butcher, H. Bluhm, M. Salmeron, G. A. Somorjai, Science 2010, 327, 850

[65] S. Wang, Y. Feng, M. Yu, Q. Wan, S. Lin, ACS Appl. Mater. Interfaces 2017, 9, 33267.

[66] V. Nicolosi, M. Chhowalla, M. G. Kanatzidis, M. S. Strano, J. N. Coleman, Science 2013, 340, 1226419

[67] J. Wan, S. D. Lacey, J. Dai, W. Bao, M. S. Fuhrer, L. Hu, Chem. Soc. Rev. 2016, 45, 6742

[68] X. Zheng, J. Xu, K. Yan, H. Wang, Z. Wang, S. Yang, Chem. Mater. 2014, 26, 2344

[69] Y. Chen, Y. Wang, S. Zhu, C. Chen, V. A. Danner, Y. Li, J. Dai, H. Li, K. K. Fu, T. Li, Y. Liu, L. Hu, ACS Appl. Mater. Interfaces 2019, 11, 6009.

[70] Y. Li, B. He, X. Liu, X. Hu, J. Huang, S. Ye, Z. Shu, Y. Wang, Z. Li, Int. J. Hydrogen Energy 2019, 44, 8070.

[71] X. Chen, Z.-Z. Lin, M. Ju, L.-X. Guo, Appl. Surf. Sci. 2019, 479, 685.

[72] Y. Luo, X. Li, X. Cai, X. Zou, F. Kang, H.-M. Cheng, B. Liu, ACS Nano 2018, 12, 4565.

[73] F. Z. Wang, M. J. Zheng, B. Zhang, C. Q. Zhu, Q. Li, L. Ma, W. Z. Shen, Sci. Rep. 2016, 6, 31092.

[74] Y.-H. Hwang, E. G. Bae, K.-S. Sohn, S. Shim, X. Song, M. S. Lah, M. Pyo, J. Power Sources 2013, 240, 683.

[75] M.-R. Gao, M. K. Y. Chan, Y. Sun, Nat. Commun. 2015, 6, 7493.

[76] Z. Gao, M. Dong, G. Wang, P. Sheng, Z. Wu, H. Yang, B. Zhang, G. Wang, J. Wang, Y. Qin, Angew. Chem., Int. Ed. 2015, 54, 9006.

[77] X. Yang, X. Yu, L. Long, T. Wang, L. Ma, L. Wu, Y. Bai, X. Li, S. Liao, Chem. Commun. 2014, 50, 2794.
[78] S. A. Miners, G. A. Rance, A. N. Khlobystov, Chem. Soc. Rev. 2016, $45,4727$.

[79] D. Iglesias, M. Melchionna, D. Iglesias, M. Melchionna, Catalysts 2019, 9, 128.

[80] W. Chen, Z. Fan, X. Pan, X. Bao, J. Am. Chem. Soc. 2008, 130, 9414

[81] W. Chen, X. Pan, M. G. Willinger, D. S. Su, X. Bao, J. Am. Chem. Soc. 2006, 128, 3136.

[82] A. D. Doyle, J. H. Montoya, A. Vojvodic, ChemCatChem 2015, 7, 738.

[83] J. Xiao, X. Pan, F. Zhang, H. Li, X. Bao, Chem. Sci. 2017, 8, 278.

[84] P. Sabatier, Ber. Dtsch. Chem. Ges. 1911, 44, 1984.

[85] J.-Y. Park, Y. Yaish, M. Brink, S. Rosenblatt, P. L. McEuen, Appl. Phys. Lett. 2002, 80, 4446

[86] F. Banhart, J. Li, M. Terrones, Small 2005, 1, 953.

[87] N. Pierard, A. Fonseca, Z. Konya, I. Willems, G. Van Tendeloo, J. B. Nagy, Chem. Phys. Lett. 2001, 335, 1.

[88] J. Liu, A. G. Rinzler, H. Dai, J. H. Hafner, R. K. Bradley, P. J. Boul, A. Lu, T. Iverson, K. Shelimov, C. B. Huffman, F. Rodriguez-Macias, Y.-S. Shon, T. R. Lee, D. T. Colbert, R. E. Smalley, Science 1998, 280, 1253.

[89] S. C. Tsang, Y. K. Chen, P. J. F. Harris, M. L. H. Green, Nature $1994,372,159$

[90] M. R. Pederson, J. Q. Broughton, Phys. Rev. Lett. 1992, 69, 2689.

[91] P. M. Ajayan, S. lijima, Nature 1993, 361, 333.

[92] D. Jain, R. Wilhelm, Carbon 2007, 45, 602.

[93] K. Schulte, J. C. Swarbrick, N. A. Smith, F. Bondino, E. Magnano, A. N. Khlobystov, Adv. Mater. 2007, 19, 3312.

[94] X. Pan, Z. Fan, W. Chen, Y. Ding, H. Luo, X. Bao, Nat. Mater. 2007 6, 507

[95] C. Wang, S. Guo, X. Pan, W. Chen, X. Bao, J. Mater. Chem. 2008, 18,5782 .

[96] G. Korneva, H. Ye, Y. Gogotsi, D. Halverson, G. Friedman, J. C. Bradley, K. G. Kornev, Nano Lett. 2005, 5, 879

[97] B. M. Weckhuysen, J. Yu, Chem. Soc. Rev. 2015, 44, 7022.

[98] S. Wu, X. Yang, C. Janiak, Angew. Chem. 2019, 131, 2.

[99] F. Gao, E. D. Walter, N. M. Washton, J. Szanyi, C. H. F. Peden, Appl. Catal., B 2015, 162, 501.

[100] M. Choi, Z. Wu, E. Iglesia, J. Am. Chem. Soc. 2010, 132, 9129.

[101] S. Goel, Z. Wu, S. I. Zones, E. Iglesia, J. Am. Chem. Soc. 2012, 134 17688

[102] N. Wang, Q. Sun, R. Bai, X. Li, G. Guo, J. Yu, J. Am. Chem. Soc. 2016, 138, 7484

[103] J. Zhang, L. Wang, B. Zhang, H. Zhao, U. Kolb, Y. Zhu, L. Liu, Y. Han, G. Wang, C. Wang, D. S. Su, B. C. Gates, F.-S. Xiao, Nat. Catal. 2018, 1, 540 .

[104] B. An, J. Zhang, K. Cheng, P. Ji, C. Wang, W. Lin, J. Am. Chem. Soc. 2017, 139, 3834

[105] J. Liu, L. Chen, H. Cui, J. Zhang, L. Zhang, C.-Y. Su, Chem. Soc Rev. 2014, 43, 6011.

[106] F. Zheng, Y. Yang, Q. Chen, Nat. Commun. 2014, 5, 5261.

[107] H.-L. Jiang, B. Liu, Y.-Q. Lan, K. Kuratani, T. Akita, H. Shioyama, F. Zong, Q. Xu, J. Am. Chem. Soc. 2011, 133, 11854.

[108] Y.-T. Xu, X. Xiao, Z.-M. Ye, S. Zhao, R. Shen, C.-T. He, J.-P. Zhang, Y. Li, X.-M. Chen, J. Am. Chem. Soc. 2017, 139, 5285.

[109] C. Lu, D. Tranca, J. Zhang, F. Rodríguez Hernández, Y. Su, X. Zhuang, F. Zhang, G. Seifert, X. Feng, ACS Nano 2017, 11, 3933.

[110] G. Li, D. Zhang, Q. Qiao, Y. Yu, D. Peterson, A. Zafar, R. Kumar, S. Curtarolo, F. Hunte, S. Shannon, Y. Zhu, W. Yang, L. Cao, J. Am. Chem. Soc. 2016, 138, 16632.

[111] I. Roger, M. A. Shipman, M. D. Symes, Nat. Rev. Chem. 2017, 1, 0003.

[112] S. Chen, J. Duan, J. Ran, M. Jaroniec, S. Z. Qiao, Energy Environ. Sci. 2013, 6, 3693.

[113] M.-X. Gu, Y. Kou, S.-C. Qi, M.-Q. Shao, M. B. Yue, X.-Q. Liu, L.-B. Sun, ACS Sustainable Chem. Eng. 2019, 7, 2837. 
[114] L. Zhang, Z.-J. Zhao, J. Gong, Angew. Chem., Int. Ed. 2017, 56, 11326.

[115] W. Wang, S. Wang, X. Ma, J. Gong, Chem. Soc. Rev. 2011, 40, 3703.

[116] E. L. Kunkes, F. Studt, F. Abild-Pedersen, R. Schlögl, M. Behrens, J. Catal. 2015, 328, 43.

[117] F. Jiao, J. Li, X. Pan, J. Xiao, H. Li, H. Ma, M. Wei, Y. Pan, Z. Zhou, M. Li, S. Miao, J. Li, Y. Zhu, D. Xiao, T. He, J. Yang, F. Qi, Q. Fu, X. Bao, Science 2016, 351, 1065.
[118] W. Li, S. Hu, X. Luo, Z. Li, X. Sun, M. Li, F. Liu, Y. Yu, Adv. Mater. 2017, 29, 1605820.

[119] E. Castillejos, P.-J. Debouttière, L. Roiban, A. Solhy, V. Martinez, Y. Kihn, O. Ersen, K. Philippot, B. Chaudret, P. Serp, Angew. Chem., Int. Ed. 2009, 48, 2529.

[120] J. Sun, H.-W. Lee, M. Pasta, H. Yuan, G. Zheng, Y. Sun, Y. Li, Y. Cui, Nat. Nanotechnol. 2015, 10, 980. 